\title{
Molecular Clustering of Phenylurea Herbicides: Comparison with Sulphonylureas, Pesticides and Persistent Organic Pollutants
}

\author{
Francisco Torrens*, Gloria Castellano** \\ * Institut Universitari de Ciència Molecular, Universitat de València, Edifici d'Instituts de Paterna, \\ P. O. Box 22085, E-46071 València, Spain \\ ** Facultad de Veterinaria y Ciencias Experimentales, Universidad Católica de Valencia San \\ Vicente Mártir, E-46001 València, Spain
} Keywords: Periodic law, Periodic property, Periodic table, Molecular classification, Information
entropy

\begin{abstract}
Chromatographic retention times of phenylurea herbicides are modelled by structure-property relationships. Properties are hydration free energy and dipole. Bioplastic evolution is an evolutionary perspective conjugating the effect of acquired characters and relations that emerge among evolutionary indeterminacy, morphological determination and natural selection principles. Classification algorithms are proposed based on information entropy and production. Phenylureas are classified by $\mathrm{Cl} 2, \mathrm{O} 2$ and N2 presence; their different behaviour depends on the number of $\mathrm{Cl}$ atoms. When applying procedures to moderate-sized sets, excessive results appear compatible with data and suffer a combinatorial explosion; however, the equipartition conjecture allows a selection criterion resulting from classification between hierarchical trees. Information entropy permits classifying compounds and agrees with principal component analyses. Phenylureas periodic table shows that those in the same group present similar properties; phenylureas also in the same period, maximum resemblance. Classification extends to phenylureas, sulphonylureas, pesticides and persistent organic pollutants.
\end{abstract}

\section{INTRODUCTION}

Phenylurea herbicides are used in formulations and for nonagrigultural use. Sørensen et al. (2008) detected residues as water contaminants. Diuron and linuron are substituted ureas, which are soluble in water, migrate in soil and enter food chain. Both are a toxicological risk to humans and wildlife. The former, which is used in cotton growing and fruit crops, is the third most hazardous pesticide for groundwater resources. Both are applied on railways to maintain quality and provide safer working environment, which leads to groundwater contamination because of leaching potential (Cederlund et al., 2007). Phenylureas enter environment via pathways, e.g., spray drift, runoff from treated fields and leaching into groundwater; they penetrate into soil where they are subjected to micro-organism action and degradation (Canonica \& Laubscher, 2008). They are unstable photochemically but they persist in water for several days or weeks depending on temperature and $\mathrm{pH}$. Pesticide pollution of water reservoirs became frequent (Berrada et al., 2004). Phenylurea residues were found in water sources, processed products and crops. In India, most soft-drink bottling plants used surface water from canals and rivers, which present pesticide contamination. Water treatment was insufficient for removal of pesticides, which were above permissible limits. Evidence was provided in a 2003 Centre for Science and Environment (CSE) report, which found several pesticide residues in many soft drinks; findings were confirmed by Joint Parliamentary Committee. In 2006, CSE conducted tests and found pesticides. Sensitive, selective and efficient methods for herbicide analysis are designed. Analytical methods are high-performance liquid chromatography (LC)-ultraviolet (HPLC-UV), solid-phase microextraction (SPME)-HPLC, diode array, immunosorbent trace enrichment and HPLC, LC-mass spectrometry (MS), gas chromatography (GC)-MS, capillary electrophoresis (Chicharro et al., 2005), photochemically induced fluorescence (FL) (Gil-García et al., 2008) and derivative spectrophotometry. Sherma (2005) reviewed thin-layer chromatography (TLC) for herbicide analysis. Muñoz de la Peña et al. (2003) and Cserháti et al. (2004) reported solid-phase extraction (SPE) of phenylurea herbicides. 
Lucena et al. (2005), Pan et al. (2005), Mumin et al. (2006), García-Reyes et al. (2008), Yoshioka \& Ichihashi (2008) and Cao et al. (2009) informed soft-drink SPE. As polar and degradablepesticide use becomes widespread, more sensitive analytical methods are developed for residual analysis in matrices. The HPLC showed advantages over GC because it is used for simultaneous analysis of thermally unstable nonvolatile, polar and neutral species without a derivative step. Because of thermally unstable nature of phenylurea herbicides, GC direct application is not possible and derivatization is needed. The HPLC with UV/FL detection was preferred over GC. Kaur et al. (2012) described a simple and sensitive HPLC-UV method for analysis of phenylurea herbicides (monuron, diuron, linuron, metazachlor, metoxuron), which involved single-step preconcentration by SPE. Phenylurea herbicidal action is based on ability to inhibit photosynthesis. Blasco \& Picó (2009) and de Aragão Umbuzeiro (2012) revised pesticides occurrence and removal efficiency in sewage treatment plants, and Moganti et al. (2008) and Barco-Bonilla et al. (2010) reported them from Spanish, Mediterranean, Brazilian and other rivers. Navarro et al. (2006) and Navarro-Ortega et al. (2010) informed transport of organic persistent microcontaminants associated with suspended particulate material in Ebro River Basin. Milian (2012) interviewed Barceló reporting that wastewater provides the only real data on drug consumption. Jadán et al. (2012) reported bioaccessibility of $\mathrm{Hg}$ and Se from swordfish.

Verhaar et al. (1992) grouped environmental pollutants into four classes (inert, less inert, reactive, specifically acting chemicals). Walker \& Nidiry (2002) reviewed current concepts in organophosphorous (OP) toxicity. Kar \& Roy (2010) provided a perspective on predictive toxicology via quantitative structure-activity relationships (QSARs). Papa \& Gramatica (2010) reported quantitative structure-property relationships (QSPRs) as a support for European Union (EU) Registration, Evaluation, Authorization and Restriction of Chemicals (REACH) regulation, rational design of environmentally safer chemicals, and Persistent, Bioaccumulative and Toxic (PBT) identification from molecular structure. Reiner et al. (2010) explained advances in analysis of persistent halogenated organic compounds. Conti et al. (2010) examined the problems facing new technologies in early toxicity assessment. Ren et al. (2010) discussed toxicity of single-wall carbon nanotubes. Lehotay (2011) reviewed quick, easy, cheap, effective, rugged and safe (QuEChERS) sample preparation approach for MS analysis of pesticide residues in foods. Raunio (2011) informed in silico toxicology and non-testing methods. Cecil et al. (2011) modelled antibiotic and cytotoxic effects of a dimeric isoquinoline on metabolism, and regulation in Staphylococcus aureus, S. epidermis and human cells. De Loof (2012) devised theoretical tools to support chemical risk assessment. Khopkar (2013) wrote an editorial on solid, hazardous, biomedical waste characterization, treatment and disposal. Wakandigara et al. (2013) discussed chemistry of phorbol ester toxicity in Jatropha curcas seed. Bertinetto et al. (2013) modelled the acute toxicity of benzene derivatives by complementary QSARs. Kubatova et al. (2013) reported effects of fullerene-60 and derivatives on selected micro-organisms. Traverso-Soto et al. (2013) analyzed alcohol polyethoxylates and polyethylene glycols in marine sediments. Leng et al. (2013) performed speciation analysis of $\mathrm{Hg}$ in sediments via HPLC-vapour generation atomic FL via microwave-assisted extraction. Wang (2013a) analyzed pesticide residues in marijuana and tea by QuEChERS/LC-MS-MS. Wang (2013b) found pesticide residues in whole milk by QuEChERS/LC-MS-MS. Melton \& Taylor (2013) investigated via LC-MS the suspected pesticide poisoning of vertebrates and beneficial insects. Askim et al. (2013) reviewed optical sensor arrays for chemical sensing and the optoelectronic nose. Barga ska et al. (2014) determined pesticide residues in honeybees via modified QuEChERS/LC-MS. Mousavi et al. (2014) applied polyacrylamide for methylene blue removal from aqueous solutions. Crunelle et al. (2014) analyzed hair ethyl glucuronide levels as a marker for alcohol use and abuse. Sheng et al. (2014) simultaneously determined antidepressant drugs and their metabolites in wastewater by ultraHPLC-MS. Lucini \& Zaza (2014) screened pesticides in water with LC-MS-MS via on-line SPE. Kinsella (2014) published an SPE for synthetic-dyes determination in seafood via LC-MS-MS. Rutkowska et al. (2014) informed microextraction in determining organomercury/tin compounds in environmental samples. In this laboratory Chulvi et al. (2012) reported discrimination of nerve 
gases mimics and OP derivatives in gas phase via a colorimetric probe array. Rowe (2014) selected the right drug candidate for accurately predicting in vivo hepatotoxicity. Oppermann \& EgelkrautHoltus characterized and quantitatively analyzed wine via spectroscopic methods. Kappes et al. (2014) informed on As poison.

In earlier publications Torrens (1999) presented aqueous coefficient calculations for chemicals and drugs. His group reported a novel approach to predict aquatic toxicity from molecular structure (Castillo-Garit, et al., 2008), atom-based quadratic indices to predict aquatic toxicity of benzene derivatives to Tetrahymena pyriformis (Castillo-Garit, et al., 2009), comparative study to predict toxic modes of action of phenols from molecular structures (Brito-Sánchez et al. 2013), atom-based quadratic indices to predict aquatic toxicity of benzene derivatives to T. pyriformis (Castillo-Garit et al., submitted for publication-a) and machine learning-based models to predict modes of toxic action of phenols from molecular structures (Castillo-Garit et al., submitted for publication-b). They informed on polymer bisphenol-A, incorporation of silica ( $\mathrm{SiO} 2)$ nanospheres into epoxy-amine materials, polymer nanocomposites (NCs) (Torrens Zaragozá, 2011), diethylstilbestrol and thermal/mechanical properties of epoxy-SiO2 NCs (Torrens \& Castellano, 2013). They described retention-time QSPRs of phenylurea herbicides (Torrens \& Castellano, 2012a, 2014a) and pesticides (Torrens \& Castellano, 2014b) by bioplastic evolution. A simple computerized algorithm is proposed for establishing chemical structure-biosignificance relation. Starting point is to use information entropy for pattern recognition. Entropy is formulated based on similarity matrix between two biochemical species. As entropy is weakly discriminating for classification, more powerful concepts of entropy production and equipartition conjecture are introduced. The aim of the present report is to review the properties that distinguish the phenylurea structures according with retention times. This study applies chemical index to phenylureas. The goal of this work is index usefulness validation via capability to distinguish phenylureas, and interest as predictive index for retention time as compared with hydration free energy and dipole moment. The following section describes the computational method. The next section illustrates and discusses the calculation results. Finally, the last section summarizes our conclusions.

\section{RESEARCH METHOD}

The problem in classification studies is to define similarity indices when several criteria of comparison are involved (Iordache, 2011, 2012, 2014). The first step in quantifying similarity for phenylureas is to list main chemical characteristics of molecules. Vector of properties $\bar{i}=$ $<i_{1}, i_{2}, \ldots i_{k}, \ldots>$ should be associated with every urea $i$, whose components correspond to different molecular features in a hierarchical order according to expected retention importance. If characteristic $m$-th is chromatographically more significant for retention than $k$-th then $m<k$. Components $i_{k}$ are either " 1 " or " 0 " according to whether a similar characteristic of rank $k$ is either present or absent in urea $i$ compared to reference. Analysis includes three characteristics in urea molecules: presence of two $\mathrm{Cl} / \mathrm{O} / \mathrm{N}$ atoms ( $c f$. Fig. 1). It is assumed that chemical characteristics of a urea molecule can be ranked according to their contribution to retention in the following order of decaying importance: $\mathrm{Cl}_{2}>\mathrm{O}_{2}>\mathrm{N}_{2}$. Index $i 1=1$ denotes $\mathrm{Cl}_{2}, i_{2}=1$ means $\mathrm{O}_{2}$ and $i_{3}=1$ signifies $\mathrm{N}_{2}$. In linuron, numbers of atoms are $\left\{\mathrm{Cl}_{2}, \mathrm{O}_{2}, \mathrm{~N}_{2}\right\}$; obviously, its vector is $<111>$. Table 1 contains vectors associated with ureas. 


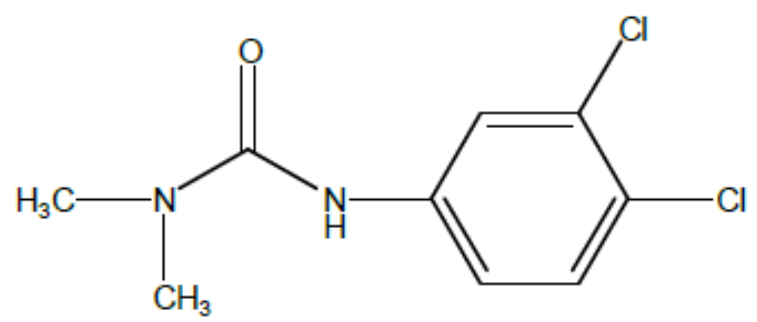

a

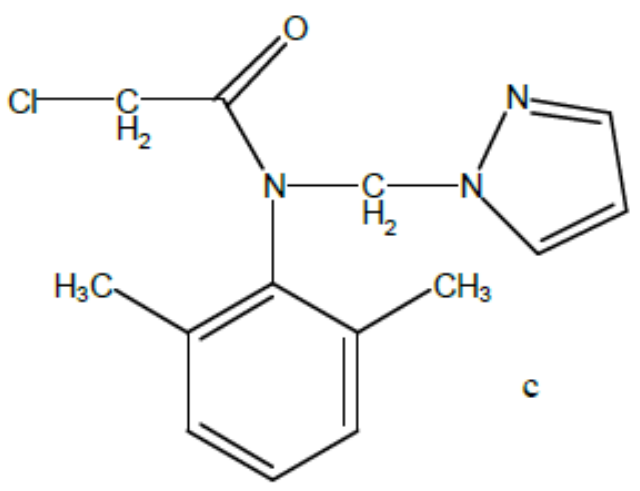

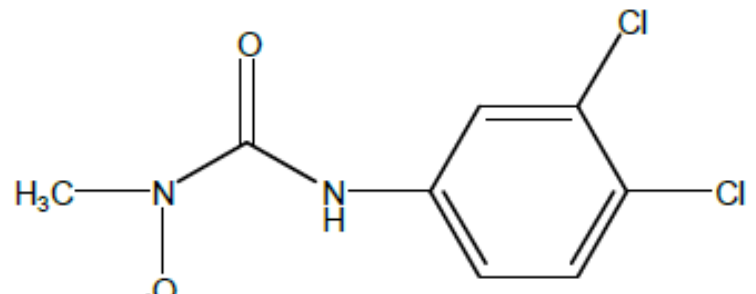

b

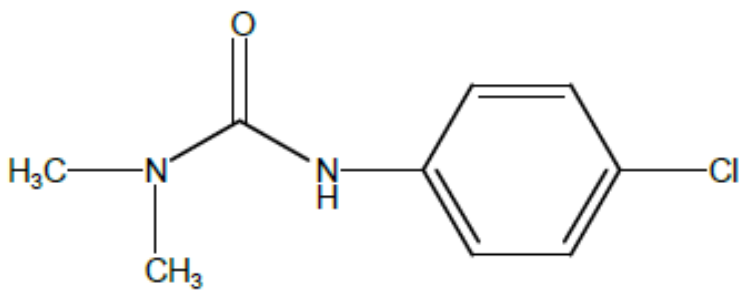

d

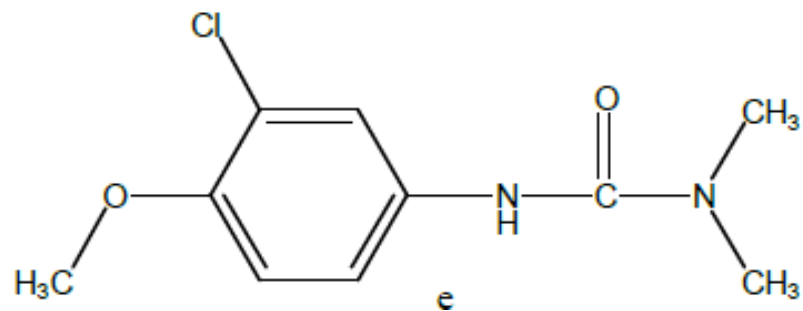

Figure 1. Phenylureas: (a) diuron; (b) linuron; (c) metazachlor; (d) monuron; (e) metoxuron

Let us denote by $r_{i j}\left(0 \leq r_{i j} \leq 1\right)$ the similarity index of two phenylureas associated with vectors $\bar{i}$ and $\vec{j}$, respectively. Similitude relationship is characterized by similarity matrix $\mathbf{R}=\left[r_{i j}\right]$. Similarity index between two ureas $\bar{i}=<i_{1}, i_{2}, \ldots i_{k} \ldots>$ and $\bar{j}=<j_{1} j_{2}, \ldots j_{k} \ldots>$ is defined as:

$$
r_{i j}=\sum_{k} t_{k}\left(a_{k}\right)^{k} \quad(k=1,2, \ldots)
$$

where $0 \leq a_{k} \leq 1$ and $t_{k}=1$ if $i_{k}=j_{k}$ but $t_{k}=0$ if $i_{k} \neq j_{k}$. The definition assigns a weight $(a k)^{k}$ to any property involved in the description of molecule $i$ or $j$. The grouping algorithm uses the stabilized matrix of similarity obtained applying max-min composition rule o defined by:

$$
(\mathbf{R} \circ \mathbf{S})_{i j}=\max _{k}\left[\min _{k}\left(r_{i k}, s_{k j}\right)\right]
$$

where $\mathbf{R}=\left[r_{i j}\right]$ and $\mathbf{S}=\left[s_{i j}\right]$ are matrices of equal type and $(\mathbf{R o S})_{i j}$ is element $(i, j)$-th of matrix $\mathbf{R o S}$. When applying max-min composition rule iteratively so that $\mathbf{R}(n+1)=\mathbf{R}(n)$ o $\mathbf{R}$ an integer $n$ exists such that: $\mathbf{R}(n)=\mathbf{R}(n+1)=\ldots$ The resulting matrix $\mathbf{R}(n)$ is called stabilized similarity matrix. Stabilization importance lies in the fact that it generates partition into disjoint classes. The stabilized matrix is designated by $\mathbf{R}(n)=\left[r_{i j}(n)\right]$. The grouping rule follows: $i$ and $j$ are assigned to the same class if $r_{i j}(n) \geq b$. The class of $i$ noted $\bar{i}$ is set of species $j$ that satisfies rule: $r_{i j}(n) \geq b$. Matrix of classes is:

$$
\widehat{\mathbf{R}}(n)=\left[\overrightarrow{r_{\hat{i j j}}}\right]=\max _{s, t}\left(r_{s t}\right) \quad(s \in \hat{i}, t \in \hat{j})
$$

where $s$ stands for any index of species belonging to class $\bar{i}$ (similarly for $t$ and $\bar{j}$ ). Rule (3) means finding largest similarity index between species of two different classes. Information entropy $h$ associated with similarity matrix $\mathbf{R}$ results: 


$$
h(\mathbf{R})=-\sum_{i, j} r_{i j} \ln r_{i j}-\sum_{i, j}\left(1-r_{i j}\right) \ln \left(1-r_{i j}\right)
$$

Every hierarchical tree corresponds to entropy dependence on grouping level and diagram $h-b$ is obtained. The equipartition conjecture of entropy production is proposed as selection criterion among different variants resulting from classification among hierarchical trees. The best dendrogram is that in which entropy production is most uniformly distributed. The equipartition line is:

$$
h_{\mathrm{eq}}=h_{\max } b
$$

Since classification is discrete, a way of expressing equipartition would be a regular staircase function. The best variant is chosen that minimizing deviation square sum:

$$
S S=\sum_{b_{1}}\left(h-h_{\text {eqp }}\right)^{2}
$$

Learning procedures similar to stochastic methods are implemented. Consider a given partition into classes as good from practical observations, which corresponds to the reference similarity matrix $\mathbf{S}=\left[s_{i j}\right]$ obtained for an arbitrary number of fictious properties. Consider also the same set of species as in the good classification and actual properties. The degree of similarity rij is computed [Eq. (1)] giving matrix $\mathbf{R}$. The number of properties for $\mathbf{R}$ and $\mathbf{S}$ differs. The learning procedure consists in finding classification results for $\mathbf{R}$ as close as possible to the good classification. The new similarity matrix is obtained [Eq. (1)]. The distance between partitions characterized by $\mathbf{R}$ and $\mathbf{S}$ results:

$$
D=-\sum_{i j}\left(1-r_{i j}\right) \ln \frac{1-r_{i j}}{1-s_{i j}}-\sum_{i j} r_{i j} \ln \frac{r_{i j}}{s_{i j}} \quad\left(\forall 0 \leq r_{i j}, s_{i j} \leq 1\right)
$$

Escultura (2013) reported theoretical and practical applications of qualitative mathematics and modelling (QMAM). Barillot et al. (2013) informed computational systems biology of cancer.

\section{RESULTS AND ANALYSIS}

For phenylureas, HPLC retention times $R \mathrm{t}$ were taken from Kaur et al. Metoxuron was reference $R_{\mathrm{t}}^{\mathrm{o}}$ because of least retention ( $c f$. Table 1); ratios $\left(R_{\mathrm{t}}-R_{\mathrm{t}}{ }^{\mathrm{o}}\right) / R_{\mathrm{t}}{ }^{\mathrm{o}}$ were calculated. Molecular dipole $\mu$ was computed with Molecular Orbital Package-Austin model 1 (MOPAC-AM1). For linuron, an alternative conformation with $1.1 \mathrm{~kJ} \cdot \mathrm{mol}^{-1}$ energy difference was used with higher dipole $\mu^{*}$.

\begin{tabular}{|c|c|c|c|c|c|}
\hline Molecule & $\begin{array}{c}R_{\mathrm{t}} \\
(\mathrm{min})\end{array}$ & $R_{\mathrm{t}}-R_{\mathrm{t}}^{\circ}(\min )$ & $\left(R_{\mathrm{t}}-R_{\mathrm{t}}^{0}\right) / R_{\mathrm{t}}^{0}$ & $\mu\left(\mu^{*}\right)(\mathrm{D})$ & $\Delta G_{\mathrm{myd}}{ }^{\circ}(\mathrm{kJ} / \mathrm{mol})$ \\
\hline 1. Metoxuron $\mathrm{N}_{2} \mathrm{O}_{2} \mathrm{Cl}_{1}<011>$ & 4.30 & 0.00 & 0.00000 & 2.872 & -16.6 \\
\hline 2. Monuron $\mathrm{N}_{2} \mathrm{O}_{1} \mathrm{Cl}_{1}<001>$ & 4.90 & 0.60 & 0.13953 & 4.612 & -21.0 \\
\hline 3. Diuron $\mathrm{N}_{2} \mathrm{O}_{1} \mathrm{Cl}_{2}<101>$ & 7.25 & 2.95 & 0.68605 & 4.622 & -22.7 \\
\hline 4. Metazachlor $\mathrm{N}_{3} \mathrm{O}_{1} \mathrm{Cl}_{1} \subset 000$ & 8.68 & 4.38 & 1.01860 & 4.740 & -23.2 \\
\hline 5. Linuron $\mathrm{N}_{2} \mathrm{O}_{2} \mathrm{Cl}_{2}<111>$ & 12.40 & 8.10 & 1.88372 & $3.999(5.077)$ & -30.3 \\
\hline
\end{tabular}
Standard Gibbs free energy of hydration $\Delta G_{\mathrm{hydr}}{ }^{\mathrm{O}}$ was calculated via program SCAP (Torrens \& Castellano, 2012b).

Table 1. Vector property $\left(\mathrm{Cl}_{2}, \mathrm{O}_{2}, \mathrm{~N}_{2}\right)$, retention, dipole and hydration energy for phenylureas

${ }^{\mathrm{a}}$ For linuron, an alternative conformation with $1.1 \mathrm{~kJ} \cdot \mathrm{mol}^{-1}$ is used ( $\mu^{*}$ between parentheses).

The $\left(R_{\mathrm{t}}-R_{\mathrm{t}}{ }^{\mathrm{o}}\right) / R_{\mathrm{t}}{ }^{\mathrm{o}}$ correlated with the dipole moment $\mu$. The fit turned out to be:

$$
\left(R_{t}-R_{t}^{\circ}\right) / R_{t}^{\circ}=-0.338+0.260 \mu, \quad n=5 \quad r=0.268 \quad s=0.843 \quad F=0.2
$$

$\mathrm{MAPE}=70.12 \% \quad \mathrm{AEV}=0.9282$

where $n$ is the number of points, $r$ Pearson correlation coefficient, $s$ standard deviation, $F$ Fischer ratio, MAPE mean absolute percentage error and AEV approximation error variance. Linuron alternative conformation improved results:

$$
\begin{aligned}
& \left(R_{t}-R_{t}^{\circ}\right) / R_{t}^{\circ}=-1.97+0.620 \mu^{*}, \quad n=5 \quad r=0.709 \quad s=0.617 \quad F=3.0 \\
& \operatorname{MAPE}=51.17 \% \quad \mathrm{AEV}=0.4977
\end{aligned}
$$


and AEV decayed by $46 \%$. Both dipoles presented fit and AEV dropped by $83 \%$. Hydration free energy $\Delta G_{\text {hydr }}{ }^{\circ}$ improved fit and AEV decreased by $91 \%$. Additional fitting parameters were tested: partition coefficients, free energies of solvation and water $\rightarrow$ organic-solvent transfer, molecular weight, volume, surface, globularity and rugosity, total and hydrophobic/philic solvent-accessible surfaces, molecular fractal dimension and that for external atoms, numbers of $\mathrm{Cl}$, total atoms and cycles, total and differential formation enthalpy, etc.; however, results did not better. Dipole inclusion allowed fit and AEV decayed by $93 \%$. Dipole $\mu^{*}$ addition permitted fitting and AEV dropped by $94 \%$. Both dipoles improved fit and AEV decreased by $98.6 \%$. Chemical indices required variables $T, S$ and $W: T$ is minus standard formation enthalpy, $S$, molecular surface and $W$, molecular weight. They allowed $I_{\mathrm{m}}=S / W$ and $I_{\mathrm{c}}=T / I_{\mathrm{m}}$. Molecular surface was computed with program TOPO (Torrens, 2003). $\left\{I_{\mathrm{m}}, I_{\mathrm{c}}\right\}$ bettered fit and AEV decayed by $78 \%$. Correction of $\left\{\mu^{*}, \Delta G_{\mathrm{hydr}}{ }^{\mathrm{o}}\right\}$ with $I \mathrm{c}$ bettered fit and AEV dropped by $98.7 \%$. Simplified analysis was obtained by hierarchical QSPR (HQSPR): variables were split into logical blocks (electronic $\left\{\mu, \mu^{*}\right\}$, solvation $\left\{\Delta G_{\mathrm{hydr}}{ }^{\mathrm{o}}\right\}$, plastic $\left.\left\{I_{\mathrm{m}}, I_{\mathrm{c}}\right\}\right)$; every block was represented by its most important variable: $\mu^{*}, \Delta G_{\mathrm{hydr}}{ }^{\mathrm{o}}$ or $I_{\mathrm{c}}$.

Pearson correlation coefficient matrix $\mathbf{R}$ was calculated between pairs of vector properties $<i_{1}, i_{2}, i_{3}>$ of five ureas. Intercorrelations are illustrated in partial correlation diagram (PCD), which contains high $(r \geq 0.75)$, medium $(0.50 \leq r<0.75)$, low $(0.25 \leq r<0.50)$ and zero $(r<0.25)$ partial autocorrelations. Pairs of ureas with higher partial correlations show similar vector property. However, the results should be taken with care because Entry 4 with constant vector $<000>$ and Entry 5 with constant vector $<111>$ show null standard deviation, causing greatest partial correlations $r=1$ with any urea, which is an artefact. With the equipartition conjecture, upper triangle resulted:

$$
\mathbf{R}=\left(\begin{array}{lllll}
0.875 & 0.625 & 0.1 \overline{2} 5^{-} & 0.500 & 0.375 \\
& 0.875 & 0.375 & 0.750 & 0.125 \\
& & 0.875 & 0.250 & 0.625
\end{array} \mid\right.
$$

Some correlations are high, e.g., $R_{2,4}=0.750$. They are illustrated in partial correlation diagram, which contains one high ( $c f$. Fig. 2, red lines), three medium (orange), three low (yellow) and three zero (black) partial correlations. Three out of four high partial correlations of Entry 4 are corrected: its correlation with Entry 1 is medium, its correlation with Entry 3 is low and its correlation with Entry 5 is zero partial correlation. All four high partial correlations of Entry 5 are corrected: correlation with Entry 3 is medium, correlation with Entry 1 is low, and correlations with Entries 2 and 4 are zero partial correlations. In all, 6 out of 7 high partial correlations of Entries 4 and 5 are corrected. 


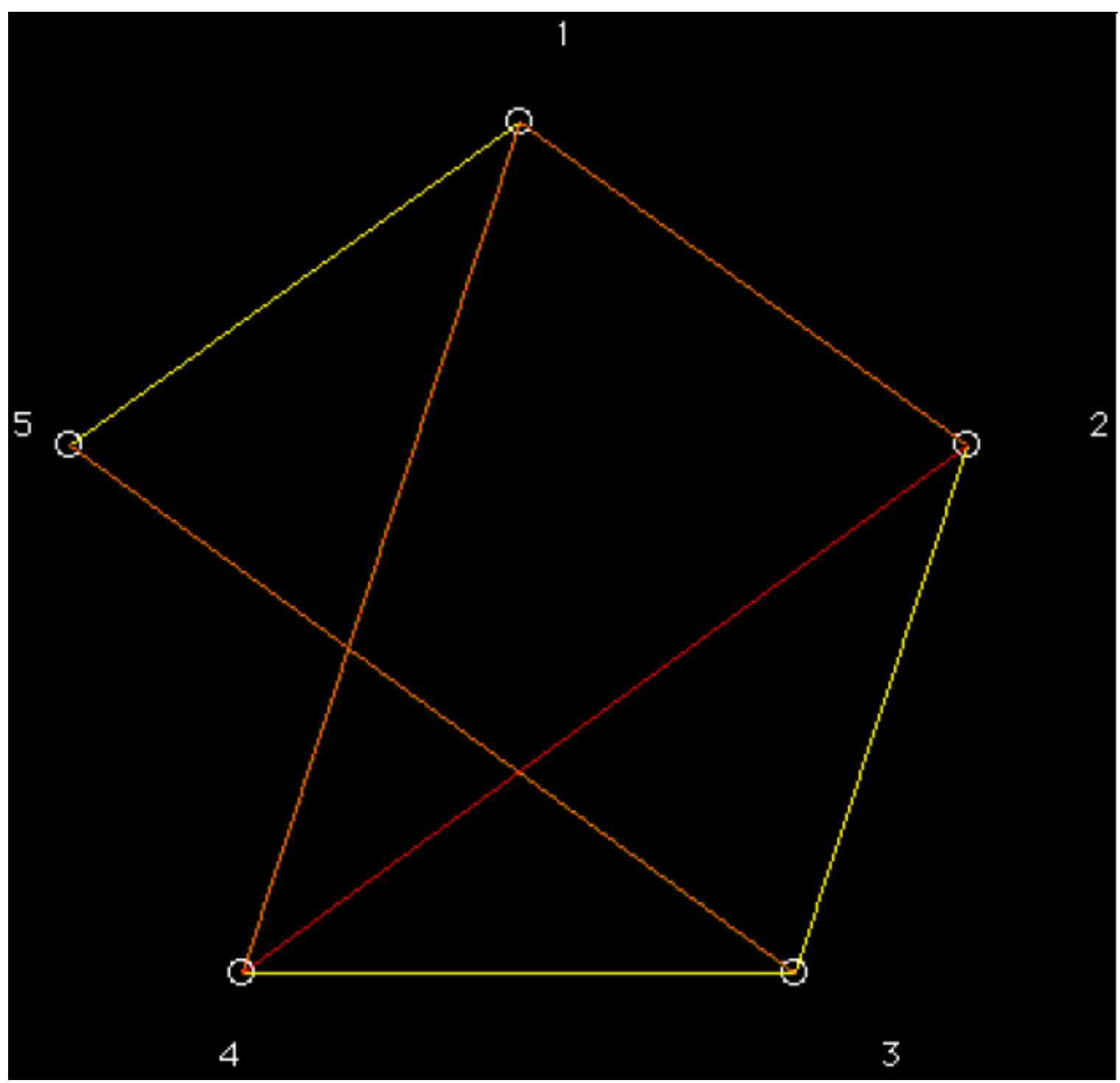

Figure 2. PCD: high (red), medium (orange) and low (yellow) correlations

Grouping rule in case with equal weights $a_{k}=0.5$ for $0.51 \leq b_{1} \leq 0.62$ allows classes: $\mathrm{C}-b_{1}=(1,2)(3,5)(4)$

Three groupings are obtained with associated entropy $h-\mathbf{R}-b_{1}=4.70$ matching to $\left\langle i_{1}, i_{2}, i_{3}>\right.$ and $\mathrm{C}-$ $b_{1}$; the binary taxonomy of Table 1 separates clusters 1, 2 and 3 with two, two and one ureas, respectively. Ureas 3 and 5 with two $\mathrm{Cl}$ atoms and great retention are grouped into the same class. Compounds belonging to the same grouping appear highly correlated in the partial correlation diagram (Fig. 2); however, $\mathrm{C}-b_{1}$ results should be taken with care because class (4) with only one substance could be an outlier. At level $b_{2}$ with $0.13 \leq b_{2} \leq 0.50$ the set of groupings is:

$\mathrm{C}-b_{2}=(1,2,4)(3,5)$

Two classes result and entropy decays to $h-\mathbf{R}-b_{2}=2.08$ matching to $<i_{1}, i_{2}, i_{3}>$ and $\mathrm{C}-b_{2}$ dividing clusters: 1 and 2 with three and two ureas. Again, ureas with $\mathrm{Cl} 2$ and great retention are grouped into the same class $(3,5)$. Ureas belonging to the same cluster appear highly correlated in the partial correlation diagram (Fig. 2). Table 2 shows a comparative analysis of set containing 1-5 classes in agreement with partial correlation diagram (Fig. 2). 
Table 2. Classification level, number of classes and entropy for phenylureas vector property

\begin{tabular}{ccc}
\hline Classification level $b$ & Number of classes & Entropy $h$ \\
\hline \hline 1.00 & 5 & 12.32 \\
0.75 & 4 & 8.31 \\
0.62 & 3 & 4.70 \\
0.50 & 2 & 2.08 \\
0.12 & 1 & 0.38 \\
\hline
\end{tabular}

From previous partial correlation diagram (Fig. 2) and set of five classifications (Table 2) we suggest to split data into three groupings:

$(1)(2,4)(3,5)$

Ureas dendrogram ( $c f$. Fig. 3) shows different behaviour depending on the number of $\mathrm{Cl}$ atoms. Once more, ureas with $\mathrm{Cl}_{2}$ and great retention are grouped into class $(3,5)$.

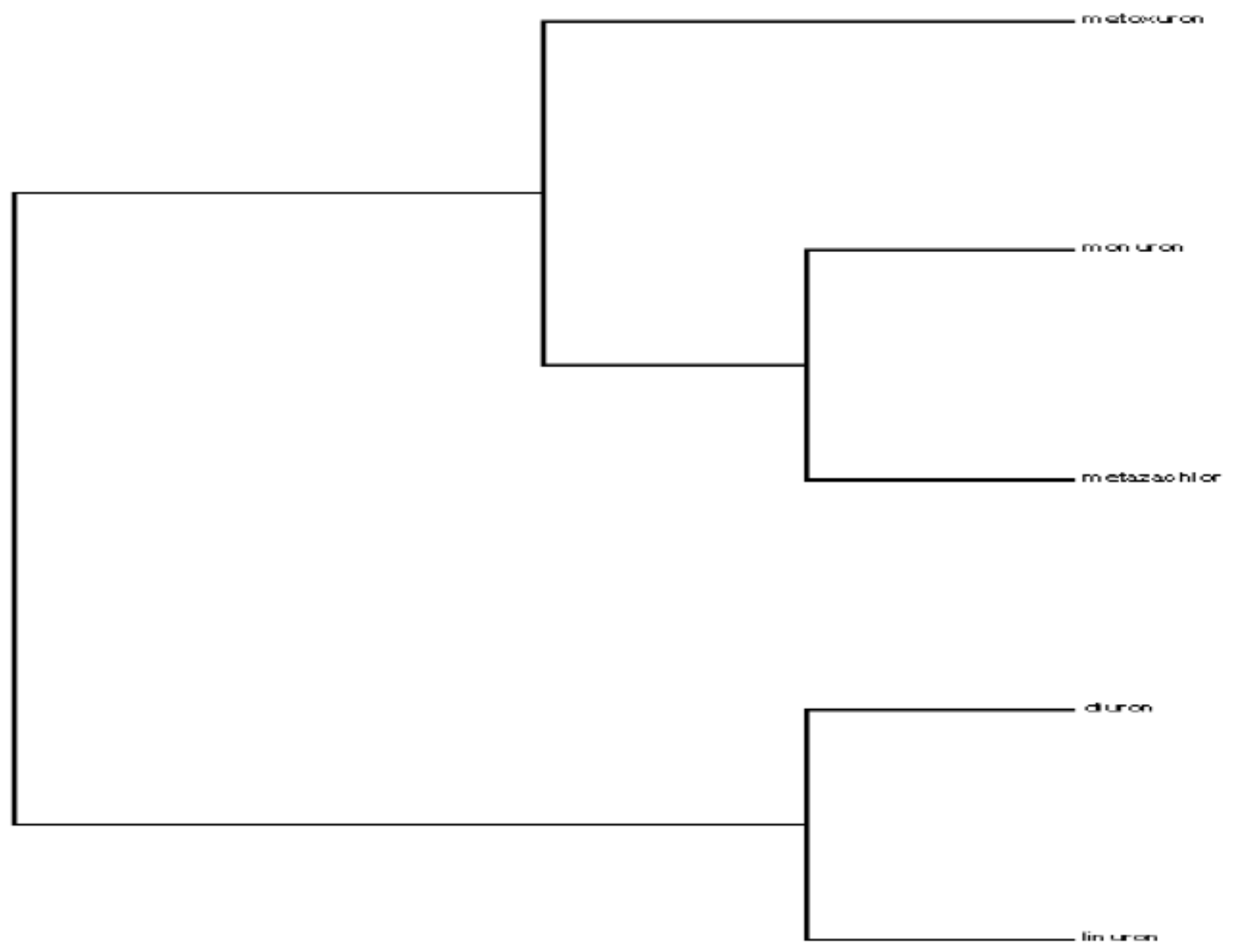

Figure 3. Dendrogram of phenylurea herbicides

The illustration of the classification above in a radial tree ( $c f$. Fig. 4) shows the different behaviour of ureas depending on the number of $\mathrm{Cl}$ atoms. The same classes above are recognized in qualitative agreement with partial correlation diagram and dendrogram (Figs. 2 and 3). One more time, ureas with $\mathrm{Cl}_{2}$ and great retention are grouped into class $(3,5)$. 


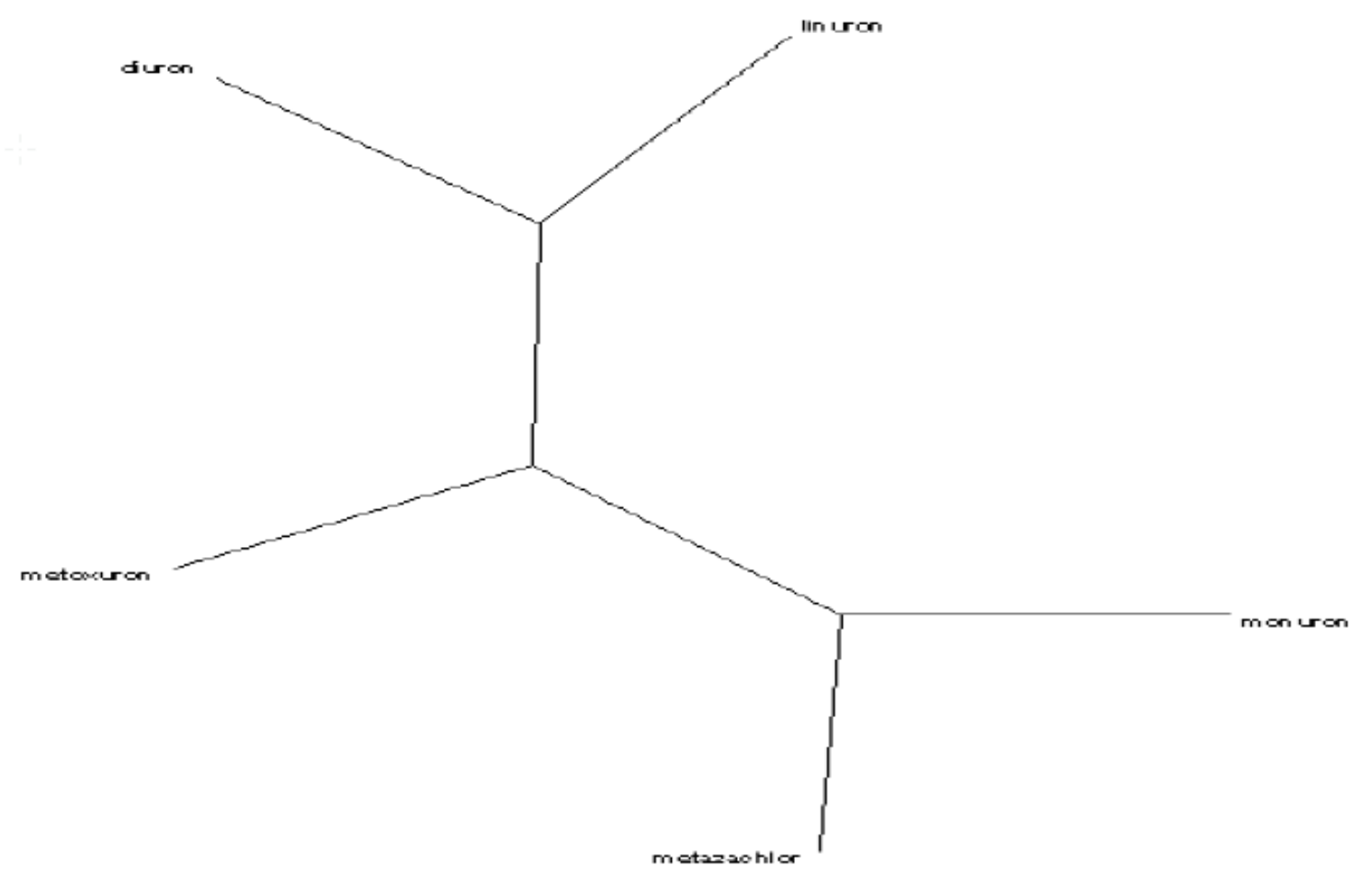

Figure 4. Radial tree of phenylurea herbicides

Program SplitsTree allows examining cluster analysis (CA) data. Based on split decomposition it takes as input a distance matrix and produces as output a graph, which represents relations between taxa. For ideal data, graph is a tree whereas less ideal data will give rise to a tree-like net, which could be interpreted as a possible evidence for conflicting data. As split decomposition does not attempt to force data onto a tree it can provide a good indication of how tree-like are given data. Splits graph for five ureas ( $c f$. Fig. 5) reveals conflicting relation between class 3 and groupings 1 and 2 because of interdependences. It indicates spurious relation from base-composition effects. It shows different urea behaviour depending on number of $\mathrm{Cl}$ atoms in qualitative agreement with partial correlation diagram and binary/radial trees (Figs. 2-4). 


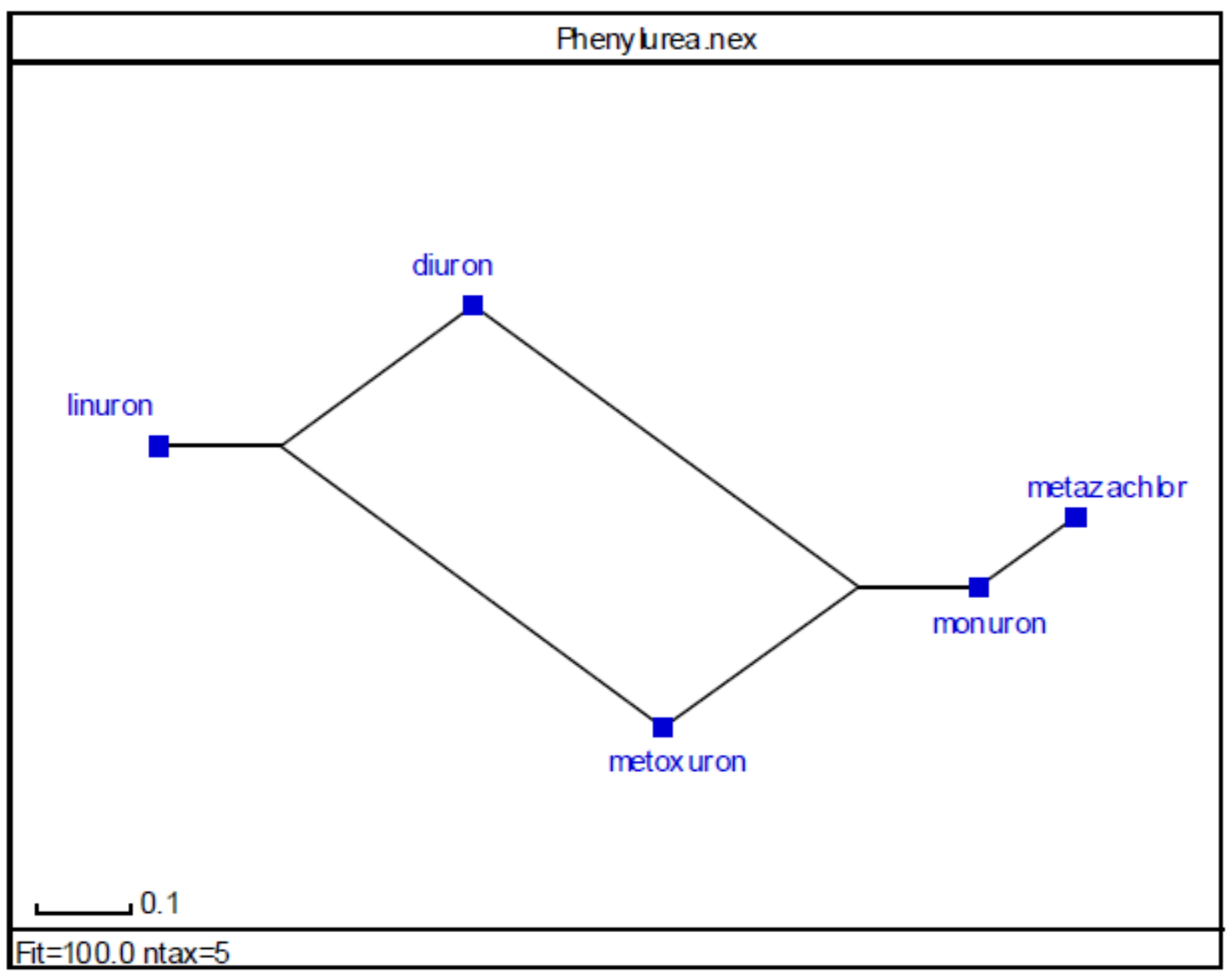

Figure 5. Splits graph of phenylurea herbicides

A principal components analysis (PCA) was performed for urea vector properties (Shaw, 2003). Importance of PCA factors $F_{1}-F_{3}$ for $\left\{i_{1}, i_{2}, i_{3}\right\}$ is collected in Table 3. Factor $F 1$ explains $56 \%$ variance ( $44 \%$ error); $F_{1 / 2}, 83 \%$ variance ( $17 \%$ error); $F_{1-3}, 100 \%$ variance $(0 \%$ error).

Table 3. Importance of principal component analysis factors for phenylurea vector property

\begin{tabular}{cccc}
\hline Factor & Eigenvalue & Percentage of variance & Cumulative percentage of variance \\
\hline$F_{1}$ & 1.66666667 & 55.56 & 55.56 \\
$F_{2}$ & 0.83333333 & 27.77 & 83.33 \\
$F_{3}$ & 0.50000000 & 16.67 & 100.00 \\
\hline
\end{tabular}

The PCA factor loadings are shown in Table 4.

Table 4. Principal component analysis loadingss for the vector property of phenylureas

\begin{tabular}{cccc}
\hline & \multicolumn{3}{c}{ PCA factor loadings $^{{ }^{2}}$} \\
\cline { 2 - 4 } Property & $F_{1}$ & $F_{2}$ & $F_{3}$ \\
\hline$i_{1}$ & 0.53452248 & 0.70710678 & 0.46291005 \\
$i_{2}$ & 0.53452248 & -0.70710678 & 0.46291005 \\
$i_{3}$ & 0.65465367 & 0.00000000 & -0.75592895 \\
\hline
\end{tabular}

${ }^{\mathrm{a}}$ Factors greater than 0.7 are boldfaced.

The PCA $F_{1}-F_{3}$ profile for vector property is listed in Table 5. For $F_{1}$ and $F_{3}$, variable $i_{3}$ shows the greatest weight in the profile; however, $F_{1}$ and $F_{3}$ cannot be reduced to two variables $\left\{i_{1}, i_{3}\right\}$ without $29 \%$ and $21 \%$ errors, respectively. For $F_{2}$, variables $\left\{i_{1}, i_{2}\right\}$ present $100 \%$ weight and $F_{2}$ is reduced to both variables with $0 \%$ error. Factors $F_{1-3}$ can be considered as linear combinations of $\left\{i_{1}, i 3\right\}$, $\left\{i_{1}, i_{2}\right\}$ and $\left\{i_{1}, i_{3}\right\}$ with $29 \%, 0 \%$ and $21 \%$ errors. 
Table 5. Profile of PCA factors for phenylurea vector property. Percentages $\geq 50 \%$ are bold

\begin{tabular}{cccc}
\hline Factor & Percentage of $i_{1}$ & Percentage of $i_{2}$ & Percentage of $i_{3}$ \\
\hline$F_{1}$ & 28.57 & 28.57 & 42.86 \\
$F_{2}$ & $\mathbf{5 0 . 0 0}$ & $\mathbf{5 0 . 0 0}$ & 0.00 \\
$F_{3}$ & 21.43 & 21.43 & $\mathbf{5 7 . 1 4}$ \\
\hline
\end{tabular}

The PCA $F_{2}-F_{1}$ scores plot for ureas (cf. Fig. 6) shows different behaviour depending on number of $\mathrm{Cl}$ atoms. It distinguishes three groupings: class 1 with one urea $\left(F_{1} \gg F_{2}\right.$, bottom), grouping 2 with two ureas $\left(F_{1}<F_{2}=0\right.$, left $)$ and class 3 with two ureas $\left(F_{1} \approx F_{2}>0\right.$, top $)$.

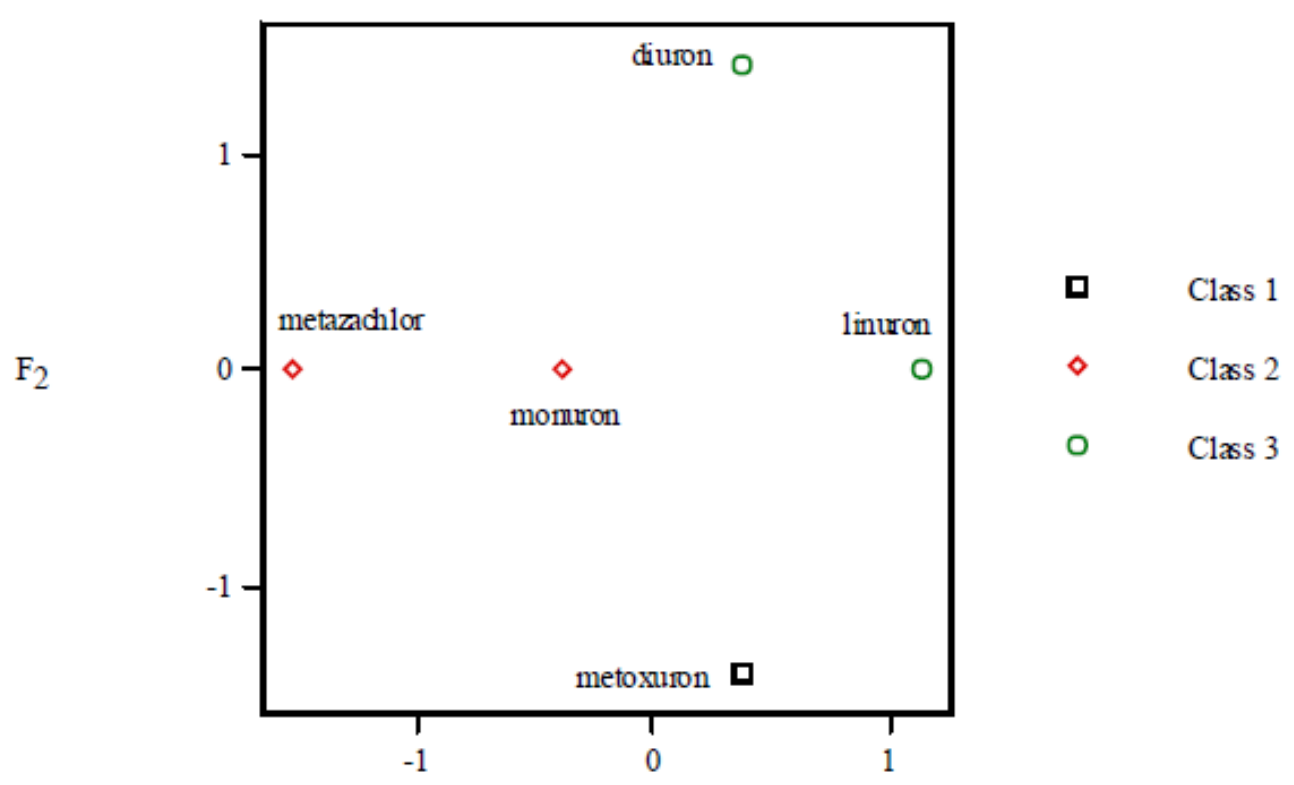

$\mathrm{F}_{1}$

Figure 6. Principal component analysis $F_{2} v s . F_{1}$ scores plot for the phenylurea herbicides

From PCA factor loadings of ureas $F_{2}-F_{1}$ loadings plot ( $c f$. Fig. 7) depicts the three properties. In addition, as a complement to the scores plot (Fig. 6) for the loadings (Fig. 7) it is confirmed that ureas in class 3 located on the top present a contribution of $\mathrm{Cl}_{2}$ situated on the same position (Fig. 6 ). The urea in grouping 1 on the bottom shows more pronounced contribution of $\mathrm{O}_{2}$. Two clusters of properties are clearly distinguished in the loadings plot: class $1\left\{\mathrm{Cl}_{2}\right\}\left(0<F_{1}<F_{2}\right.$, Fig. 7, top $)$ and grouping $2\left\{\mathrm{O}_{2}, \mathrm{~N}_{2}\right\}\left(F_{1}>>F_{2}\right.$, bottom). 


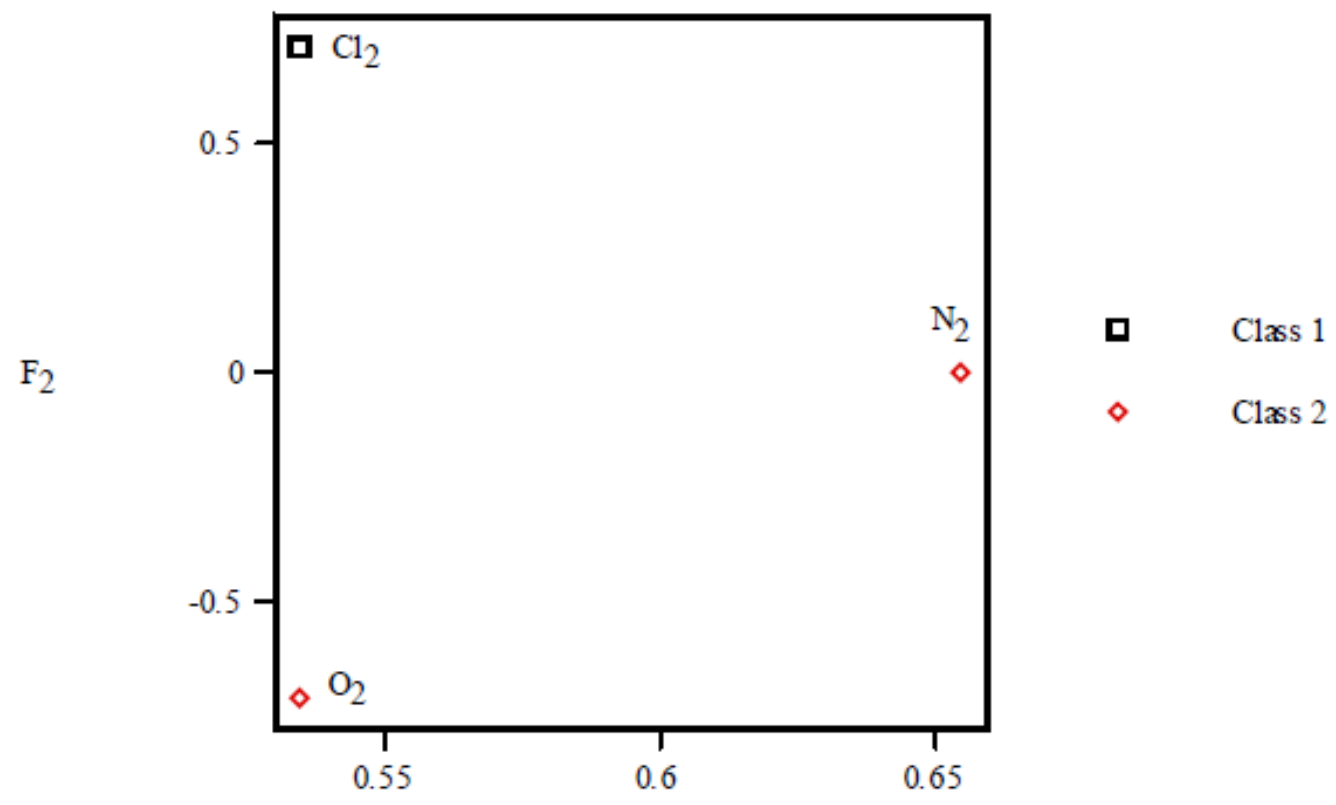

$F_{1}$

Figure 7. Principal component analysis $F 2$ vs. $F 1$ loadings plot for the phenylurea herbicides

Instead of five ureas in the $\mathfrak{R}^{3}$ space of three vector properties, consider three properties in the $\mathfrak{R}^{5}$ space of five ureas. The upper triangle of matrix $\mathbf{R}$ between pairs of properties resulted:

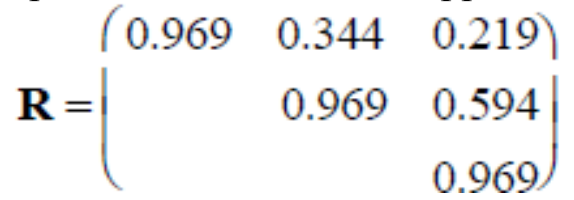

Some correlations are relatively high, e.g., $R_{2,3}=0.594$. All are represented in partial correlation diagram, which contains one medium ( $c f$. Fig. 8, orange), one low (yellow) and one zero (black) partial correlations.

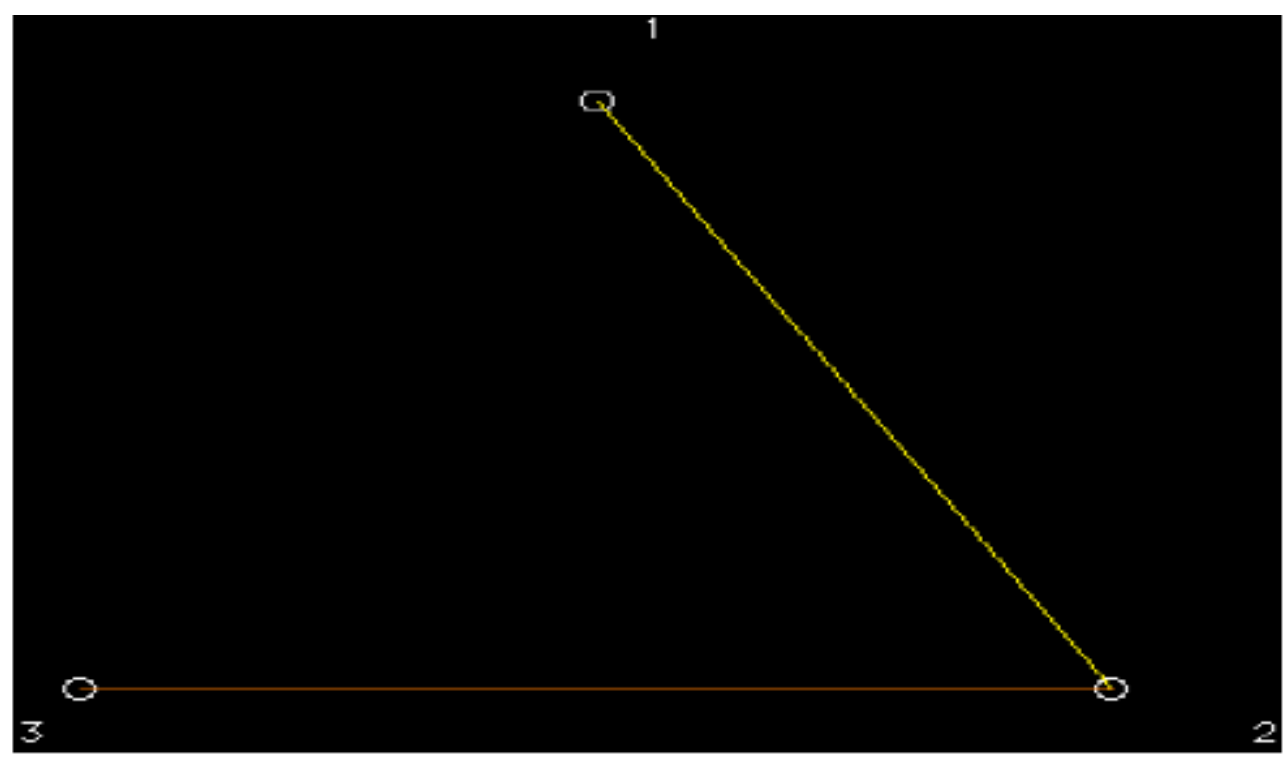

Figure 8. PCD for properties: medium (orange); low (yellow) correlations

Dendrogram for vector properties ( $c f$. Fig. 9) separates first $\mathrm{Cl}_{2}$ (class 1) and then $\mathrm{O}_{2}$ from $\mathrm{N}_{2}$ (grouping 2), in agreement with PCA loadings plot and partial correlation diagram (Figs. 7 and 8). 
Figure 9. Dendrogram for the vector properties corresponding to phenylurea herbicides

The radial tree for the vector properties ( $c f$. Fig. 10) separates the same two classes as PCA loadings plot, partial correlation diagram and dendrogram (Figs. 7-9). 


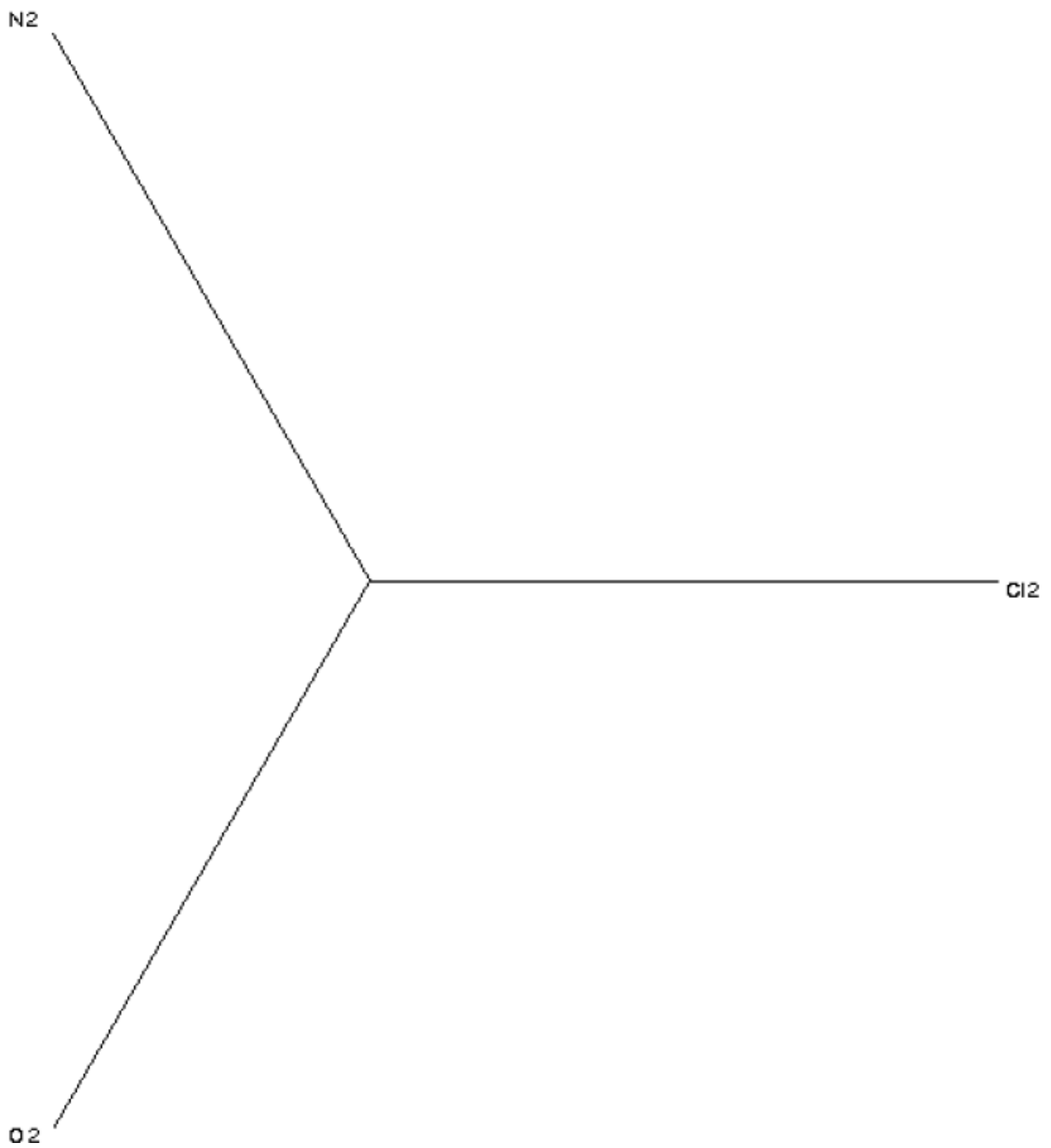

Figure 10. Radial tree for the vector properties corresponding to phenylurea herbicides

Splits graph for properties ( $c f$. Fig. 11) reveals no conflicting relation between vector components. It is in agreement with PCA loadings plot, partial correlation diagram and binary/radial trees (Figs. 7-10). 


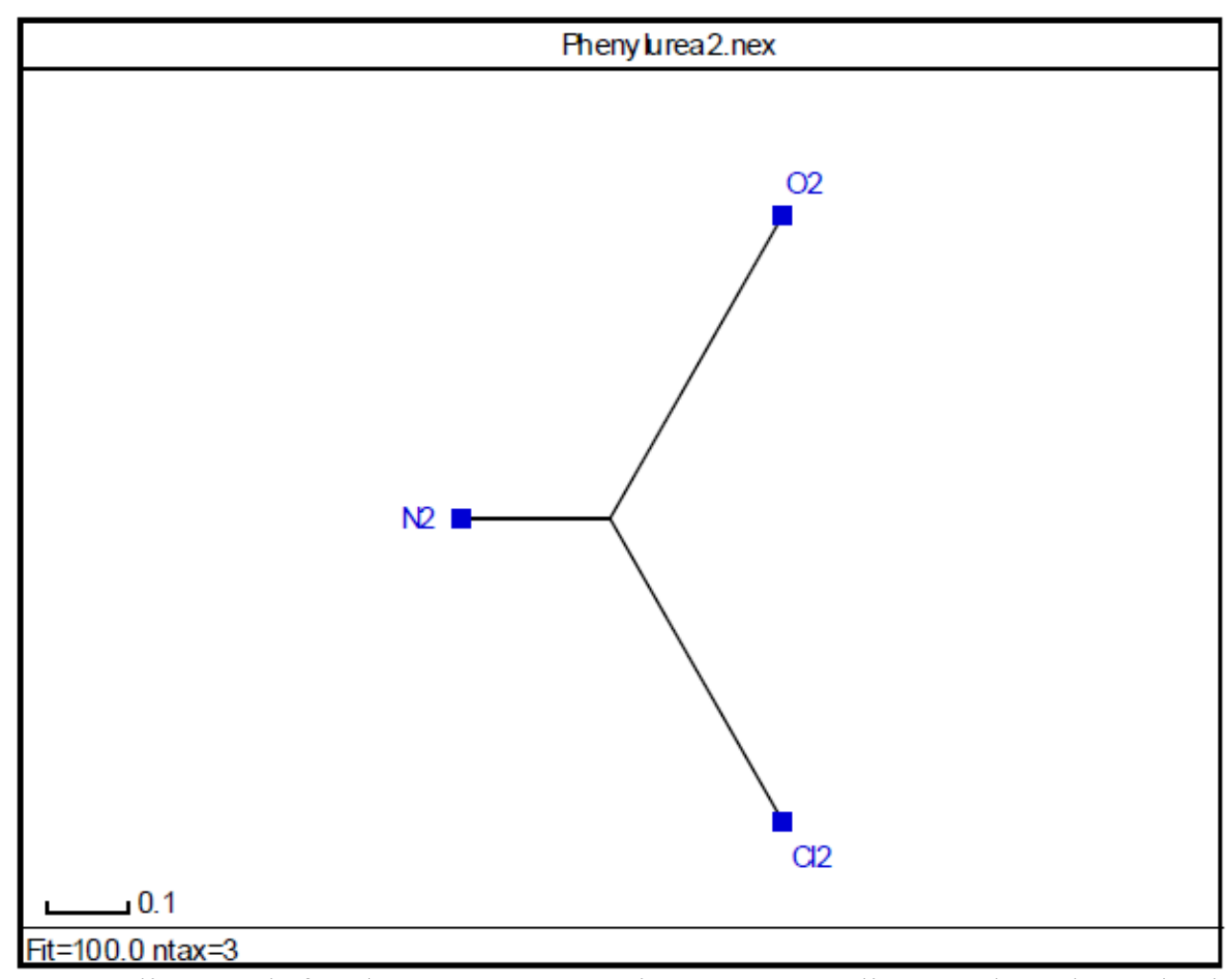

Figure 11. Splits graph for the vector properties corresponding to phenylurea herbicides

A PCA was performed for vector properties. Factor $F_{1}$ explains $61 \%$ of variance (39\% error), factors $F_{1 / 2}$ account for $83 \%$ of variance (17\% error), factors $F_{1-3}$ rationalize $96 \%$ of variance $(4 \%$ error), etc. In PCA $F_{2}-F_{1}$ scores plot the same two clusters of properties are distinguished: class 1 $\left\{\mathrm{Cl}_{2}\right\}\left(0>F_{1}>F_{2}\right.$, cf. Fig. 12, bottom $)$ and grouping $2\left\{\mathrm{O}_{2}, \mathrm{~N}_{2}\right\}\left(F_{1}<F_{2}\right.$, top $)$ in agreement with PCA loadings plot, partial correlation diagram, binary/radial trees and splits graph (Figs. 7-11).

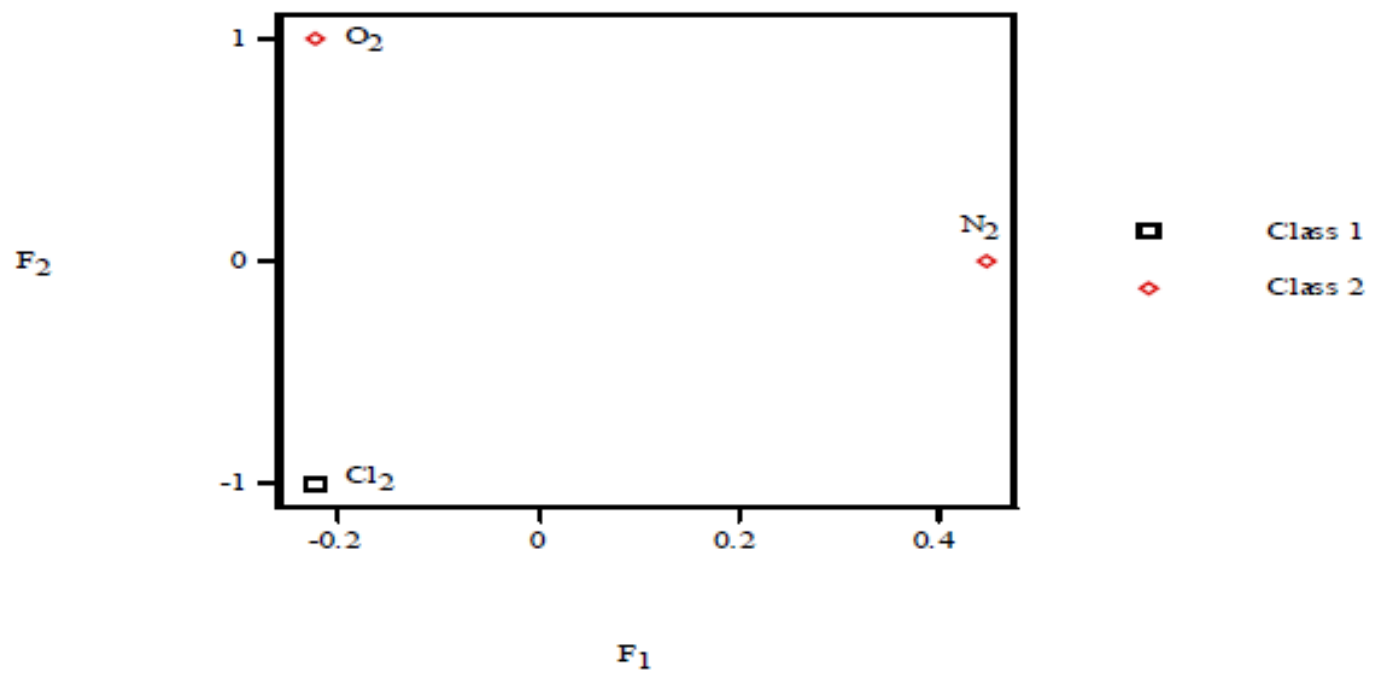

Figure 12. PCA F2 vs. F1 scores plot for vector properties corresponding to phenylureas

The recommended format of phenylureas periodic table (PT, $c f$. Table 6) shows that they are classified first by $i_{1}, i_{2}$ and, finally, by $i_{3}$. Vertical groups are defined by $\left\langle i_{1}, i_{2}>\right.$ and horizontal periods, by $\left\langle i_{3}>\right.$. Periods of four units are assumed; e.g., group g00 stands for $\left.\left\langle i_{1}, i_{2}\right\rangle=<00\right\rangle$ : $<000>\left(\mathrm{Cl}_{1}, \mathrm{O}_{1}, \mathrm{~N}_{3}\right)$ and $<001>\left(\mathrm{Cl}_{1}, \mathrm{O}_{1}, \mathrm{~N}_{2}\right)$, etc. Ureas in the same column appear close in partial correlation diagram, binary/radial trees, splits graph and PCA scores (Figs. 2-6). Can et al. (2013) determined sulphonylurea and phenylurea-herbicide toxicities with quantitative structure-toxicity relationships (QSTRs). Table 6 includes 27 sulphonylurea and phenylurea herbicides: metazachlor is similar to sulphonylureas, monuron matches most phenylureas and diuron goes with phenylurea neburon. Wang \& Telepchak (2013) determined pesticides in red wine by QuEChERS extraction, 
rapid mini-cartridge cleanup and LC-MS-MS detection. Table 6 comprises eight pesticides: (1) metazachlor corresponds thiabendazole, pyrimethanil, cyprodinil, pyrazophos and chlorpyrifos; (2) monuron goes with diazinone. Cabrera \& Altmaier (2013) reported high-resolution and ultratrace analysis of pesticides via $\mathrm{SiO}_{2}$ monoliths. Table 6 takes in six new pesticides: (1) metazachlor ties in with metamitron, carbofuran and prometryne; (2) monuron fits carbetamide and isoproturon; (3) methamidophos agrees with metolachlor. Forster \& Altmaier (2013) informed qualitative LC-MS analysis of pesticides via monolithic $\mathrm{SiO} 2$ capillaries and potential for pesticide assay in kidney. Table 6 contains two novel pesticides: metazachlor tallies chlorfenvinphos and monuron equals pencycuron. Nold (2009) provided analytical standards for persistent organic pollutants (POPs). Bruggemann \& Annoni (2014) discussed average heights in partially ordered sets. Table 6 embraces five POPs: metazachlor equals lindane, 2,2',4,4',5-pentabromodiphenylether(BDE-99), chlordecone, pentachlorobenzene and perfluoroctane sulphonate (PFOS).

Table 6. Periodic properties table of phenyl/sulphonylurea herbicides, pesticides and POPs

\begin{tabular}{|c|c|c|c|c|}
\hline Period & $\mathrm{g} 00$ & $\mathrm{~g} 01$ & $\mathrm{~g} 10$ & g11 \\
\hline $\mathrm{p} 0$ & 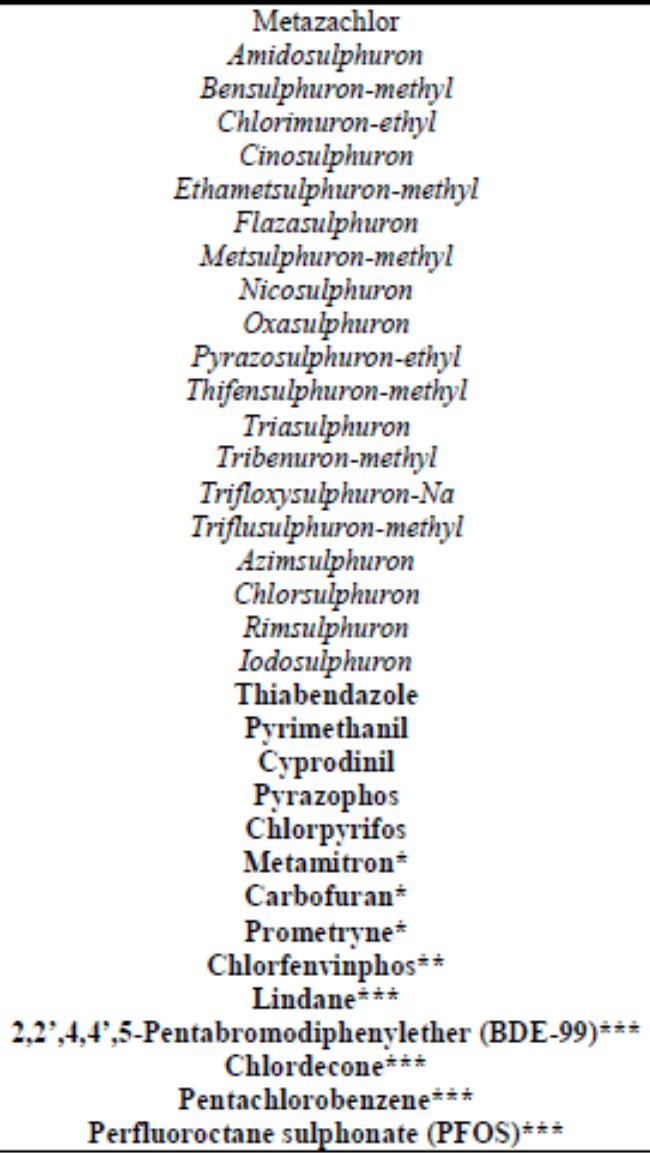 & $\begin{array}{l}\text { Methamidophos } \\
\text { Carbendazim } \\
\text { Metolachlor* }\end{array}$ & & \\
\hline p1 & $\begin{array}{c}\text { Monuron } \\
\text { Buturon } \\
\text { Chlorotoluron } \\
\text { Daimuron } \\
\text { Fenuron } \\
\text { Methyldimuron } \\
\text { Fluometuron } \\
\text { Siduron } \\
\text { Diazinone } \\
\text { Carbetamide* } \\
\text { Isoproturon" } \\
\text { Pencycuron }\end{array}$ & Metoxuron & $\begin{array}{l}\text { Diuron } \\
\text { Neburon }\end{array}$ & Linuron \\
\hline
\end{tabular}

Regular: phenylurea herbicides.

Italics: sulphonylurea herbicides.

Bold: pesticides.

Bold*: pesticides.

Bold**: pesticides.

Bold $* * *$ : persistent organic pollutants. 
Property $P$ variation ( $c f$. Fig. 13) of vector $\left\langle i_{1}, i_{2}, i_{3}>\right.$ is expressed in the decimal system $P=10^{2} i_{1}$ $+10 i_{2}+i_{3} v s$. structural parameters $\left\{i_{1}, i_{2}, i_{3}\right\}$ for ureas. Property was not used in PT (Table 6) development and serves to validate it. Most points appear superimposed. Results show a parameters hierarchy: $i_{1}>i_{2}>i_{3}$ in agreement with property PT with vertical groups defined by $\left\{i_{1}, i_{2}\right\}$ and horizontal periods, by $\left\{i_{3}\right\}$.

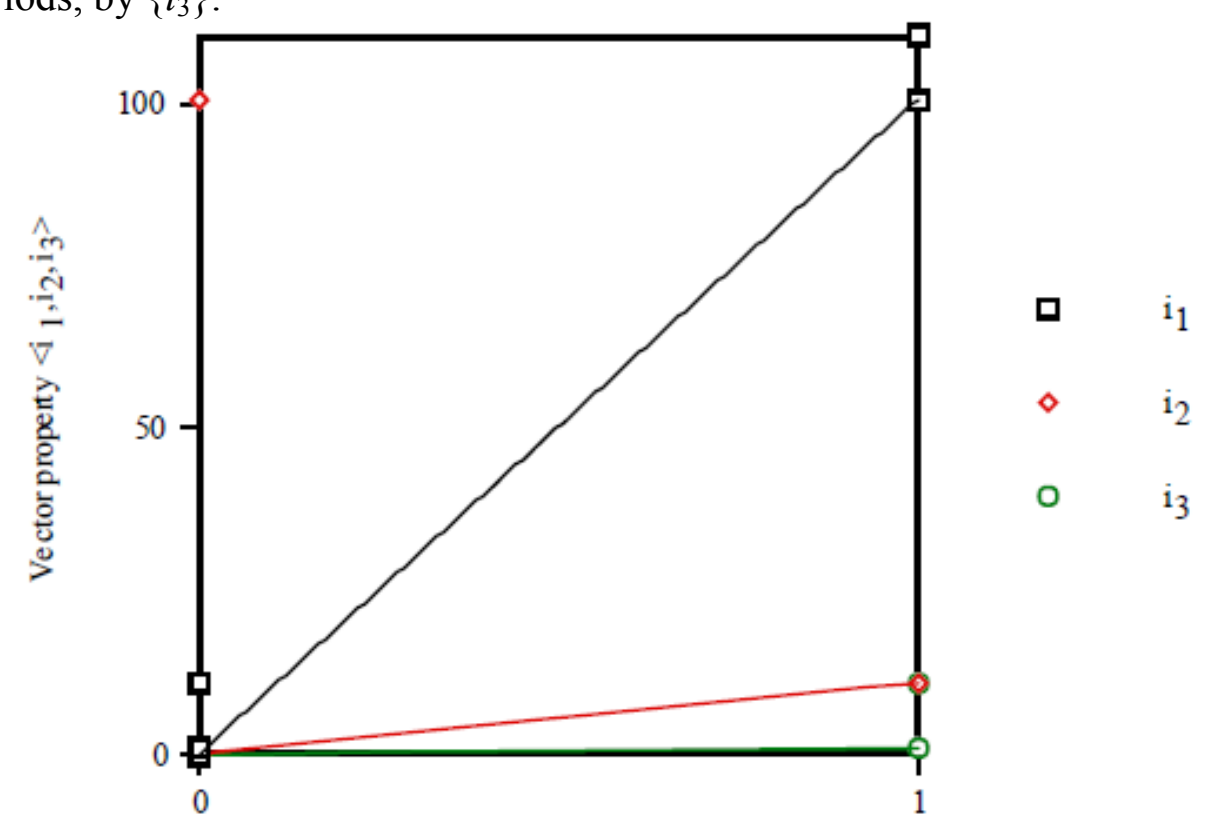

Structural parameter

Figure 13 . Variation of property $P(p)$ of phenylurea herbicides $v s$. counts $\left\{i_{1}, i_{2}, i_{3}\right\}$

Property $P$ change of vector $<i_{1}, i_{2}, i_{3}>$ in base 10 (cf. Fig. 14) vs. the number of group in PT, for ureas, reveals minima corresponding to compounds with $<i_{1}, i_{2}>c a .<00>$ (group g00) and maxima with $<i_{1}, i_{2}>c a .<11>$ (group g11). For group 1 , period 2 is superimposed on 1 . Periods $\mathrm{p} 0$ and $\mathrm{p}_{1}$ represent rows 1 and 2 , respectively, in Table 6 . Corresponding function $P\left(i_{1}, i_{2}, i_{3}\right)$ denotes two periodic waves clearly limited by minima and maxima, which suggest a periodic behaviour that recalls the form of a trigonometric function. For $\left\langle i_{1}, i_{2}, i_{3}\right\rangle$, a minimum is clearly shown. The distance in $<i_{1}, i_{2}, i_{3}>$ units between each pair of consecutive minima is four, which coincides with urea sets in successive periods. The minima occupy analogous positions in the curve and are in phase. The representative points in phase should correspond to elements in the same group in PT. For minima, $<i_{1}, i_{2}, i_{3}>$ coherence exists between the two representations; however, consistency is not general. Wave comparison shows two differences: period 1 is incomplete and period 2 is somewhat staircase-like. Most characteristic points of the plot are minima, which lie about group g00. Values $\left\langle i_{1}, i_{2}, i_{3}>\right.$ are repeated as periodic law (PL) states. 


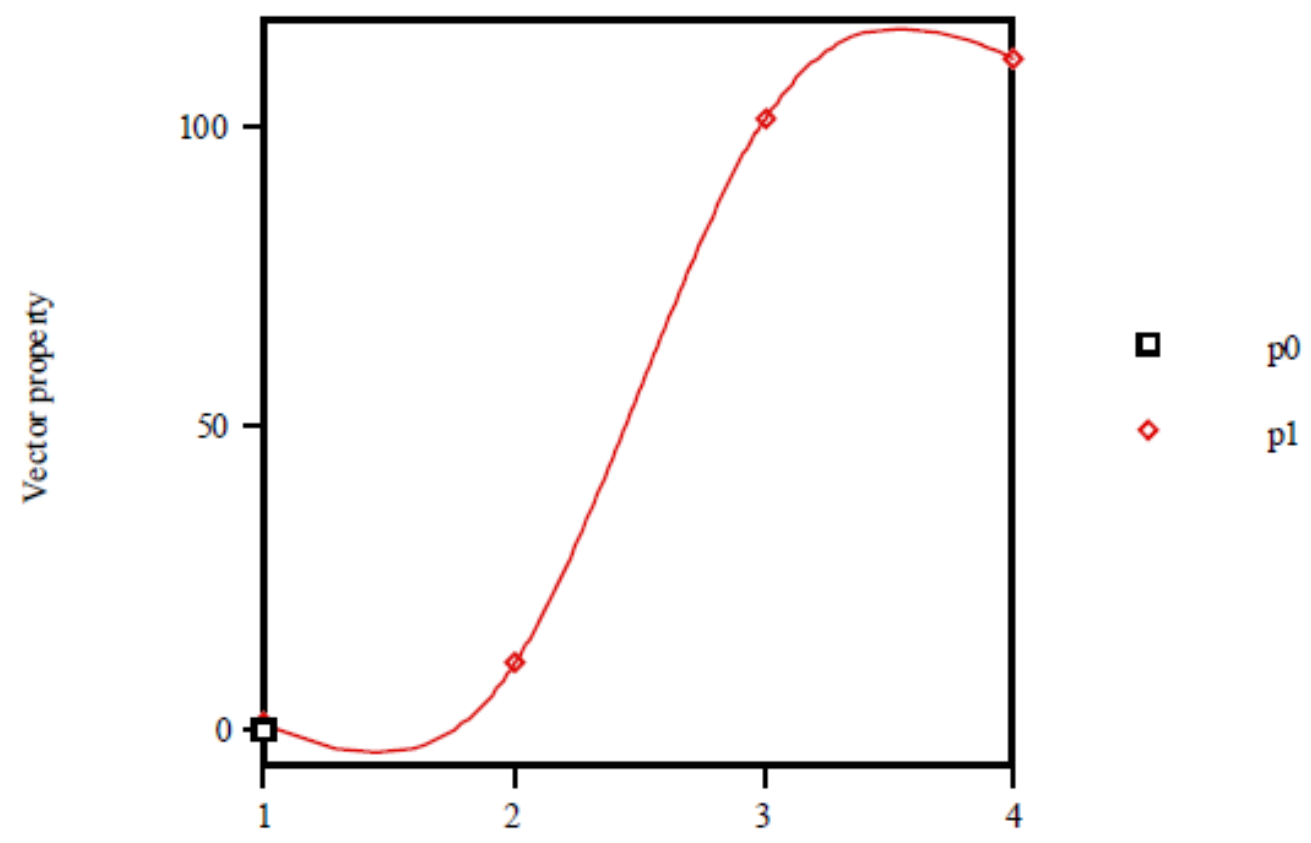

Group number

Figure 14. Variation of property $P(p)$ of phenylurea herbicides $v s$. group number

An empirical function $P(p)$ reproduces different $<i_{1}, i_{2}, i_{3}>$ values. Minimum of $P(p)$ has meaning only if it is compared with former $P(p-1)$ and later $P(p+1)$ points needing to fulfil:

$$
\begin{aligned}
& P_{\min }(p)<P(p-1) \\
& P_{\min }(p)<P(p+1)
\end{aligned}
$$

Order relations (10) should repeat at intervals equal to period size and are equivalent to:

$$
\begin{aligned}
& P_{\min }(p)-P(p-1)<0 \\
& P(p+1)-P_{\min }(p)>0
\end{aligned}
$$

As relations (11) are valid only for minima, others more general are desired for all $p$ values. The differences $D(p)=P(p+1)-P(p)$ are calculated assigning every value to phenylurea $p$ :

$$
D(p)=P(p+1)-P(p)
$$

Instead of $D(p), R(p)=P(p+1) / P(p)$ can be taken allocating them to urea $p$. If PL were general, elements in the same group in analogous positions in different periods would satisfy:

either $D(p)>0$ or $D(p)<0$

and either $R(p)>1$ or $R(p)<1$

However, results show that this is not the case so that PL is not general existing some anomalies; e.g., $D(p)$ variation $v s$. group number ( $c f$. Fig. 15) presents a lack of coherence between $\left\langle i_{1}, i_{2}, i_{3}>\right.$ Cartesian and PT representations. If consistency were rigorous, all points in each period would present the same sign. In general, a trend exists to give $D(p)>0$, especially for the lower groups. 


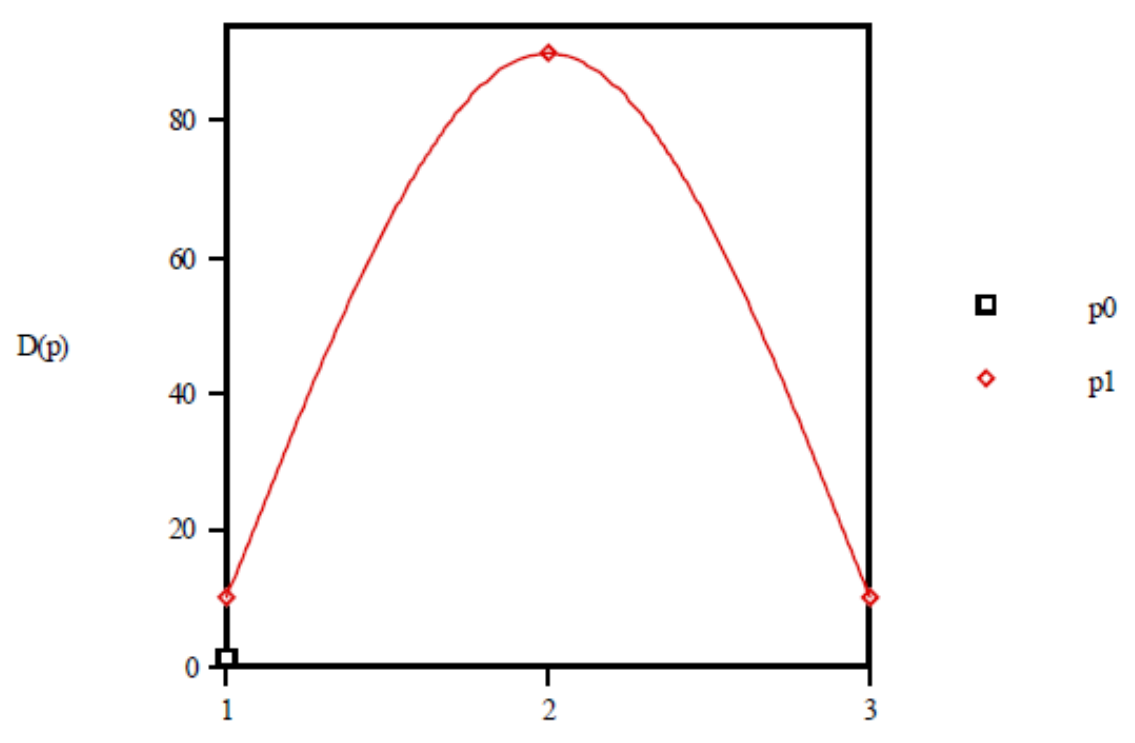

Figure 15 . Variation of property $D(p)=P(p+1)-P(p)$ vs. group. $P$ is vector property

Change of $R(p) v s$. group number ( $c f$. Fig. 16) confirms the lack of constancy between Cartesian and PT charts. If steadiness were exact all points in each period would show $R(p)$ either lesser or greater than one. A trend exists to give $R(p)>1$, especially for the lower groups.

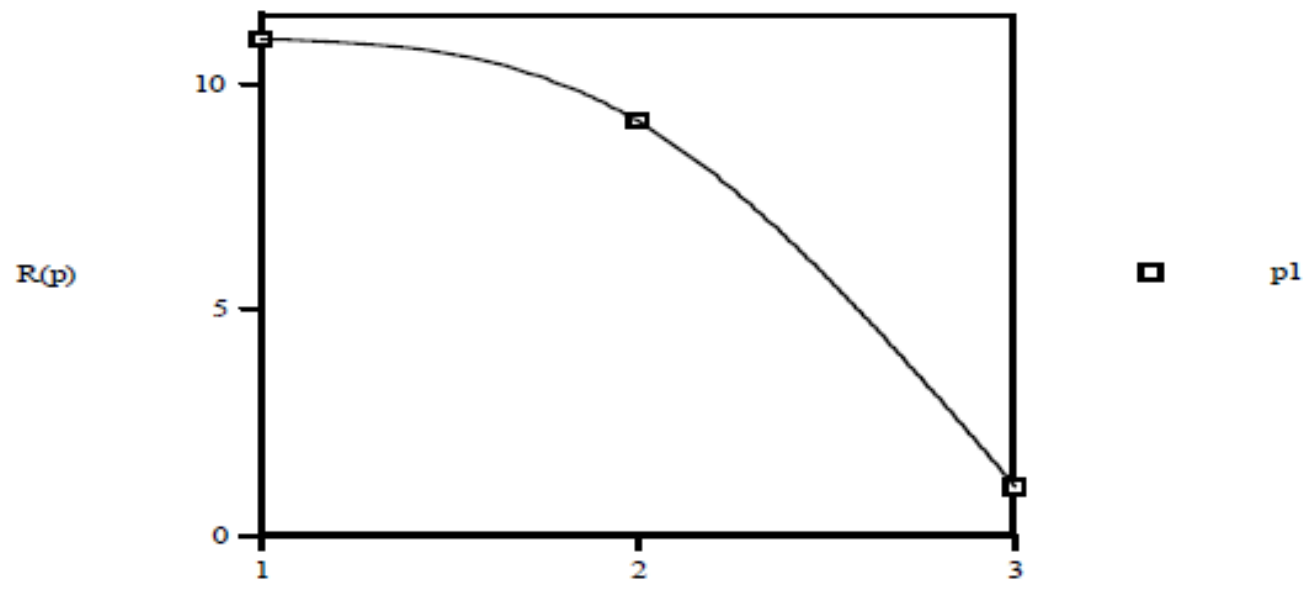

Group number

Figure 16. Variation of property $R(p)=P(p+1) / P(p) v s$. group number. $P$ is vector property

\section{CONCLUSION}

From the present results and discussion the following conclusions can be drawn.

1. Objective was to develop a structure-property model for qualitative and quantitative prediction of phenylureas retention. Results contribute to pesticide residue prediction in food and environmental samples. Program SCAP allows hydration and solvation free energies. Hydration free energy and dipole differentiated ureas. An alternative conformation above global minimum was used with higher dipole. Parameters needed for co-ordination index are molar formation enthalpy, weight and surface area. Morphological and co-ordination indices improved correlations for retention. Co-ordination index was predictive for retention when used with others. Correlation between molecular area and weight points to a homogeneous molecular structure of ureas, and 
ability to predict and tailor herbicide properties; the latter is nontrivial in environmental toxicology. A hierarchical quantitative structure-property relation provided properties simplified analyses.

2. Criteria selected to reduce the analysis to a manageable quantity of phenylureas referred to structural characteristics related to presence of two $\mathrm{O}, \mathrm{N}$ and, especially, $\mathrm{Cl}$ atoms. Classification agreeded with principal component analyses. Program MolClas is a simple, reliable, efficient and fast procedure for molecular categorization based on equipartition conjecture of entropy production. It was written not only to analyze the equipartition conjecture of entropy production but also to explore the world of molecular clustering.

3. Periodic law does not satisfy physics-law status: (a) phenylureas retentions are not repeated; perhaps chemical character; (b) order relations are repeated with exceptions. The analysis forces the statement: The relations that any compound $p$ has with its neighbour $p+1$ are approximately repeated for each period. Periodicity is not general; however, if substance natural order is accepted the law must be phenomenological. Retention is not used in periodic-table generation and serves to validate it. Other-property analysis would give insight into possible generality of periodic table. Periodic classification was extended to phenylureas, sulphonylureas, pesticides and persistent organic pollutants.

Work is in progress on the quantitative structure-antioxidant activity models of isoflavonoids from Dalbergia parviflora.

\section{ACKNOWLEDGEMENTS}

One of us, F. T., thanks support from the Spanish Ministerio de Economía y Competitividad (Project No. BFU2013-41648-P) and EU ERDF.

\section{REFERENCES}

[1] Askim, J. R., Mahmoudi, M., \& Suslick, K. S. (2013). Optical sensor arrays for chemical sensing: The optoelectronic nose. Chemical Society Reviews, 42, 8649-8682.

[2] Barco-Bonilla, N., Romero-González, R., Plaza-Bolaños, P., Garrido Frenich, A., \& Martínez Vidal, J. L. (2010). Analysis and study of the distribution of polar and non-polar pesticides in wastewater effluents from modern and conventional treatments. Journal of Chromatography, A, $1217,7817-7825$.

[3] Barga $\sim$ ska, Q., Ílebioda, M., \& Namießnik, J. (2014). Determination of pesticide residues in honeybees using modified QUEChERS sample work-up and liquid chromatography-tandem mass spectrometry. Molecules, 19, 2911-2924.

[4] Barillot, E., Calzone, L., Hupe, P., Vert, J.-P., \& Zinovyev, A. (2013). Computational systems biology of cancer. Boca Raton, FL: CRC.

[5] Berrada, H., Font, G., \& Moltó, J. C. (2004). Application of solid-phase microextraction for determining phenylurea herbicides and their homologous anilines from vegetables. Journal of Chromatography, A, 1042, 9-14.

[6] Bertinetto, C., Duce, C., Solaro, R., Tiné, M. R., Micheli, A., Héberger, K., Miliçevi $\approx$, A., \& Nikoli $\approx$, S. (2013). Modeling of the acute toxicity of benzene derivatives by complementary QSAR methods. MATCH Communications in Mathematical and in Computer Chemistry, 70, 1005-1021.

[7] Blasco, C., \& Picó, Y. (2009). Prospects for combining chemical and biological methods for integrated environmental assessment. Trends in Analytical Chemistry, 28, 745-757.

[8] Brito-Sánchez, Y., Castillo-Garit, J. A., Le-Thi-Thu, H., González-Madariaga, Y., Torrens, F., Marrero-Ponce, Y., \& Rodríguez-Borges, J. E. (2013). Comparative study to predict toxic modes of action of phenols from molecular structures. SAR \& QSAR in Environmental Research, 24, 235251.

[9] Bruggemann, R., \& Annoni, P. (2014). Average heights in partially ordered sets. MATCH Commun. MATCH Communications in Mathematical and in Computer Chemistry, 71, 117-142. 
[10] Cabrera, K., \& Altmaier, S. (2013). High-resolution and ultra trace analysis of pesticides using silica monoliths. International Labmate, 38(6), 4-5.

[11] Can, A., Yildiz, I., \& Guvendik, G. (2013). The determination of toxicities of sulphonylurea and phenylurea herbicides with quantitative structure-toxicity relationship (QSTR) studies. Environmental Toxicology and Pharmacology, 35, 369-379.

[12] Canonica, S., \& Laubscher, H. U. (2008). Inhibitory effect of dissolved organic matter on triplet-induced oxidation of aquatic contaminants. Photochemical \& Photobiological Sciences, 7 , 547-551.

[13] Cao, X. L., Corriveau, J., \& Popovic, S. (2009). Levels of bisphenol A in canned soft drink products in Canadian markets. Journal of Agricultural and Food Chemistry, 57, 1307-1311.

[14] Castillo-Garit, J. A., Abad, C., Marrero-Ponce, Y., Torrens, F., Escobar, J., \& Torreblanca, A. (submitted for publication-a). Atom-based quadratic indices to predict aquatic toxicity of benzene derivatives to Tetrahymena pyriformis. Ecotoxicology and Environmental Safety.

[15] Castillo-Garit, J. A.. Casañola-Martin, G. M., Marrero-Ponce, Y., Torrens, F., \& Torreblanca, A. (submitted for publication-b). Machine learning based models to predict modes of toxic action of phenols from molecular structures. Journal of Computer-Aided Molecular Design.

[16] Castillo-Garit, J. A., Escobar, J., Marrero-Ponce, Y., \& Torrens, F. (2009). Atom-based quadratic indices to predict aquatic toxicity of benzene derivatives to Tetrahymena pyriformis. In: J. A. Seijas, M. P. Vázquez Tato (Eds.), Synthetic organic chemistry (Vol. 13, pp. 1-26). Basel, Switzerland: MDPI.

[17] Castillo-Garit, J. A., Marrero-Ponce, Y., Escobar, J., Torrens, F., \& Rotondo, R. (2008). A novel approach to predict aquatic toxicity from molecular structure. Chemosphere, 73, 415-427.

[18] Cecil, A., Rikanovi , C., Ohlsen, K., Liang, C., Bernhardt, J., Oelschlaeger, T. A., Gulder, T., Bringmann, G., Holzgrabe, U., Unger, M., \& Dandekar, T. (2011). Modeling antibiotic and cytotoxic effects of the dimeric isoquinoline IQ-143 on metabolism and its regulation in Staphylococcus aureus, Staphylococcus epidermis and human cells. Genome Biology, 12, R24-118.

[19] Cederlund, H., Börjesson, E., Önneby, K., \& Stenström, J. (2007). Metabolic and cometabolic degradation of herbicides in the fine material of railway ballast. Soil Biology \& Biochemistry, 39, 473-484.

[20] Chicharro, M., Bermejo, E., Sanchez, A., Zapardiel, A., Fernandez-Gutierrez, A., \& Arraez, D. (2005). Multiresidue analysis of phenylurea herbicides in environmental waters by capillary electrophoresis using electrochemical detection. Analytical and Bioanalytical Chemistry, 382, 519526.

[21] Chulvi, K. Gaviña, P. Costero, A. M. Gil, S., Parra, M., Gotor, R., Royo, S., Martínez-Máñez, R., Sancenón, F., \& Vivancos, J.-L. (2012). Discrimination of nerve gases mimics and other organophosphorous derivatives in gas phase using a colorimetric probe array. Chemical Communications, 48, 10105-10107.

[22] Conti, M., Matar, C., Ismail, A., \& Franck, J. (2010). Tackling toxicity. European Biopharmaceutical Review, 2010(4), 40-41.

[23] Crunelle, C. L., Yegles, M., van Nuijs, A. L. N., Covaci, A., De Doncker, M., Maudens, K. E., Sabbe, B., Dom, G., Lambert, W. E., Michielsen, P., \& Neels, H. (2014). Hair ethyl glucuronide levels as a marker for alcohol use and abuse: A review of the current state of the art. Drug and Alcohol Dependence, 134, 1-11.

[24] Cserháti, T., Forgács, E., Deyl, Z., Miksik, I., \& Eckhardt, A. (2004). Chromatographic determination of herbicide residues in various matrices. Biomedical Chromatography, 18, 350-359.

[25] De Aragão Umbuzeiro, G. (Ed.). (2012). Guia de potabilidade para substàncias químicas. São Paulo, Brazil: Limiar. 
[26] De Loof, K., Rademaker, M., Bruggemann, R., De Meyer, H., Restrepo, G., \& De Baets, B. (2012). Order-theoretical tools to support risk assessment of chemicals. MATCH Communications in Mathematical and in Computer Chemistry, 67, 213-230.

[27] Escultura, E. (2013). Qualitative mathematics and modeling: Theoretical and practical applications of QMAM. Saarbrücken, Germany: Lap Lambert.

[28] Forster, S., \& Altmaier, S. (2013). Qualitative LC-MS analysis of pesticides using monolithic silica capillaries and potential for assay of pesticides in kidney. LC GC Europe, 26, 488-496.

[29] García-Reyes, J. F., Gilbert-López, B., Molina-Díaz, A., \& Fernández-Alba, A. R. (2008). Determination of pesticide residues in fruit-based soft drinks. Analytical Chemistry, 80, 8966-8974.

[30] Gil-García, M. D., Martínez-Galera, M., Parrilla-Vázquez, P., Mughari, A. R., \& OrtizRodríguez, I. M. (2008). Application of the Doehlert design to optimize the signal obtained in photochemically induced fluorescence for the determination of eight phenylureas. Journal of Fluorescence, 18, 365-373.

[31] Iordache, O. (2011). Modeling multi-level systems. Berlin, Germany: Springer.

[32] Iordache, O. (2012). Self-evolvable systems: Machine learning in social media. Berlin, Germany: Springer.

[33] Iordache, O. (2014). Polytope projects. Boca Raton, FL: CRC.

[34] Jadán, C., Vélez, D., \& Devesa, V. (2012). Bioaccessibility of Hg and Se from swordfish. Paper presented at the 2nd Workshop Food Safety, València, Spain.

[35] Kappes, S., Moser, R., \& Zumbrägel, B. (2014). The multipurpose poison. Labmate, Buyers Guide, 48-49.

[36] Kar, S., \& Roy, K. (2010). Predictive toxicology using QSAR: A perspective. Journal of the Indian Chemical Society, 87, 1455-1515.

[37] Kaur, M., Malik, A. K., \& Singh, B. (2012). Determination of phenylurea herbicides in tap water and soft drink samples by HPLC-UV and solid-phase extraction. LC GC Europe, 25, 120129.

[38] Khopkar, S. M. (2013). Solid, hazardous, biomedical waste-characterization, treatment and disposal. Research Journal of Chemistry and Environment, 17(6), 1-4.

[39] Kinsella, B. (2014). A simple SPE method for the determination of malachite green, crystal violet, and other synthetic dyes in seafood using LC-MS-MS. LC·GC Europe, 27(3), 161-161.

[40] Kubatova, H., Zemanova, E., Klouda, K., Bilek, K., \& Kadukova, J. (2013). Effects of C60 fullerene and its derivatives on selected microorganisms. Journal of Microbiology Research, 3, 152162.

[41] Lehotay, S. J. (2011). QuEChERS sample preparation approach for mass spectrometric analysis of pesticide residues in foods. In J. Zweigenbaum (Ed.), Mass spectrometry in food safety (pp. 65-91). Totowa, NJ: Humana.

[42] Leng, G., Feng, L., Li, S.-B., Yang, P., \& Dan, D.-Z. (2013). Speciation analysis of mercury in sediments using HPLC hyphenated to vapour generation atomic fluorescence spectrometry following microwave-assisted extraction. LC.GC Europe, 26, 250-258.

[43] Lucena, R., Cárdenas, S., Gallego, M., \& Valcárcel, M. (2005). Continuous flow autoanalyzer for the sequential determination of total sugars, colorant and caffeine contents in soft drinks. Analytica Chimica Acta, 530, 283-289.

[44] Lucini, S. M., \& Zaza, S. (2014). Screening of pesticides in water with LC-MS-MS using online SPE. LC·GC Europe, 27(3), 157-158.

[45] Melton, L., \& Taylor, M. (2013). The use of liquid chromatography tandem mass spectrometry for the investigation of suspected (pesticide) poisoning of vertebrate animals and beneficial insects. Spectroscopy Europe, 25(4), 12-14. 
[46] Milian, À. (2012). L'estudi de l'aigua residual dóna les úniques dades reals de consum de droga. Temps, (1474), 38-39.

[47] Moganti, S., Richardson, B. J., McClellan, K., Martin, M., Lam, P. K. S., \& Zheng, G. J. (2008). Use of the clam Asaphis deflorata as a potential indicator of organochlorine bioaccumulation in Hong Kong coastal sediments. Marine Pollution Bulletin, 57, 672-680.

[48] Mousavi, H. Z., Khaligh, A., Behzad, M., \& Rahchamani, J. (2014). Application of polyacrylamide for methylene blue removal from aqueous solutions. Journal of Applied Solution Chemistry and Modeling, 3, 39-47.

[49] Mumin, A., Akhter, K. F., Abedin, Z., \& Hossain, Z. (2006). Determination and characterization of caffeine in tea, coffee and soft drinks by solid phase extraction and high performance liquid chromatography (SPE-HPLC). Malaysian Journal of Chemistry, 8, 45-51.

[50] Muñoz de la Peña, A., Mahedero, M. C., \& Bautista-Sánchez, A. (2003). Monitoring of phenylurea and propanil herbicides in river water by solid-phase-extraction high performance liquid chromatography with photoinduced-fluorimetric detection. Talanta, 60, 279-285.

[51] Navarro, A., Tauler, R., Lacorte, S., \& Barceló, D. (2006). Chemometrical investigation of the presence and distribution of organochlorine and polyaromatic compounds in sediments of the Ebro River Basin. Analytical and Bioanalytical Chemistry, 385, 1020-1030.

[52] Navarro-Ortega, A., Tauler, R., Lacorte, S., \& Barceló, D. (2010). Occurrence and transport of PAHs, pesticides and alkylphenols in sediment samples along the Ebro River Basin. Journal of Hydrology, 383, 5-17.

[53] Nold, M. (2009). Analytical standards for persistent organic pollutants. Analytix, (5), 11-12.

[54] Oppermann, U., \& Egelkraut-Holtus, M. (2014). In wine there is truth - The characterisation and quantitative analysis of wine using spectroscopic methods. Labmate, Buyers Guide, 8-10.

[55] Pan, Z., Wang, L., Mo, W., Wang, C., Hu, W., \& Zhang, J. (2005). Determination of benzoic acid in soft drinks by gas chromatography with on-line pyrolytic methylation technique. Analytica Chimica Acta, 545, 218-223.

[56] Papa, E., \& Gramatica, P. (2010). QSPR as a support for the EU REACH regulation and rational design of environmentally safer chemicals: PBT identification from molecular structure. Green Chemistry, 12, 836-843.

[57] Raunio, H. (2011). In silico toxicology - non-testing methods. Frontiers in Pharmacology, 2 , 33-1-8.

[58] Reiner, E. J., Boden, A. R., Chen, T., MacPherson, K. A., \& Muscalu, A. M. (2010). Advances in the analysis of persistent halogenated organic compounds. LC GC Europe, 23, 60-70.

[59] Ren, H.-X., Chen, X., Liu, J.-H., Gu, N., \& Huang, X.-J. (2010). Toxicity of single-walled carbon nanotube: How we were wrong? Materials Today, 13(1-2), 6-8.

[60] Rowe, C. (2014). Selecting the right drug candidate: Accurately predicting in vivo hepatotoxicity. Genetic Engineering \& Biotechnology News, 34(8), 14-15.

[61] Rutkowska, M., Dubalska, K., Konieczka, P., \& Namießnik. J. (2014). Microextraction techniques used in the procedures for determining organomercury and organotin compounds in environmental samples. Molecules, 19, 7581-7609.

[62] Shaw, P. J. A. (2003). Multivariate statistics for the environmental sciences. New York, NY: Hodder-Arnold.

[63] Sheng, L.-H., Chen, H.-R., Huo, Y.-B., Wang, J., Zhang, Y., Yang, M., Zhang, H.-X. (2014). Simultaneous determination of 24 antidepressant drugs and their metabolites in wastewater by ultrahigh performance liquid chromatography-tandem mass spectrometry. Molecules, 19, 1212-1222.

[64] Sherma, J. (2005). Thin-layer chromatography of pesticides - A review of applications for 2002-2004. Acta Chromatographica, 15, 5-30. 
[65] Sørensen, S. R., Albers, C. N., \& Aamand, J. (2008). Rapid mineralization of the phenylurea herbicide diuron by Variovorax sp. strain SRS16 in pure culture and within a two-member consortium. Applied and Environmental Microbiology, 74, 2332-2340.

[66] Torrens, F. (1999). Aqueous coefficient calculations for chemicals and drugs. Toxicological and Environmental Chemistry, 73, 177-189.

[67] Torrens, F. (2003). Characterizing cavity-like spaces in active-site models of zeolites. Computational Materials Science, 27, 96-101.

[68] Torrens, F., \& Castellano, G. (2012a). QSPR prediction of retention times of phenylurea herbicides by biological plastic evolution. Current Drug Safety, 7, 262-268.

[69] Torrens, F., \& Castellano, G. (2012b). Estimation of partition coefficients of Fe-S protein models: Se substitutions in Fe4S4Cysn. Journal of Chemistry and Chemical Engineering, 6, 867877.

[70] Torrens, F., \& Castellano, G. (2013). Bisphenol, diethylstilbestrol, polycarbonate and the thermomechanical properties of epoxy-silica nanostructured composites. Journal of Research Updates in Polymer Science, 2, 183-193.

[71] Torrens, F., \& Castellano, G. (2014a). Molecular classification of pesticides including persistent organic pollutants, phenylurea and sulphonylurea herbicides. Molecules, 19, 7388-7414.

[72] Torrens, F., \& Castellano, G. (2014b). QSPR prediction of chromatographic retention times of pesticides: Partition and fractal indices. Journal of Environmental Science and Health, Part B, 49, 400-407.

[73] Torrens Zaragozá, F. (2011). Polymer bisphenol-A, the incorporation of silica nanospheres into epoxy-amine materials and polymer nanocomposites. Nereis, 2011(3), 17-23.

[74] Traverso-Soto, J. M., Lara-Martín, P. A., León, V. M., \& González-Mazo, E. (2013). Analysis of alcohol polyethoxylates and polyethylene glycols in marine sediments. Talanta, 110, 171-179.

[75] Verhaar, H. J. M., van Leeuwen, C. J., \& Hermens, J. L. M. (1992). Classifying environmental pollutants. Chemosphere, 25, 471-491.

[76] Wakandigara, A., Nhamo, L. R. M., \& Kugara, J. (2013). Chemistry of phorbol ester toxicity in Jatropha curcas seed - A review. International Journal of Biochemistry Research \& Review, 3, 146-161.

[77] Walker Jr., B., \& Nidiry, J. (2002). Current concepts: Organophosphate toxicity. Inhalation Toxicology, 14, 975-990.

[78] Wang, X. (2013a). Determination of pesticide residues in marijuana and tea by QuEChERS and LC-MS-MS. LC·GC Europe, 26, 414-414.

[79] Wang, X. (2013b). Determination of pesticide residues in whole milk by QuEChERS and LCMS-MS. LC·GC Europe, Applications Book(9), 9-9.

[80] Wang, X., \& Telepchak, M. J. (2013). Determination of pesticides in red wine by QuEChERS extraction, rapid mini-cartridge cleanup and LC-MS-MS detection. LC GC Europe, 26, 66-76.

[81] Yoshioka, N., \& Ichihashi, K. (2008). Determination of 40 synthetic food colors in drinks and candies by high-performance liquid chromatography using a short column with photodiode array detection. Talanta, 74, 1408-1413. 